\title{
Organoimido-Polyoxometalate Nonlinear Optical Chromophores: A Structural, Spectroscopic, and Computational Study
}

\author{
Ahmed Al-Yasari, ${ }^{\dagger, \nabla}$ Nick Van Steerteghem, ${ }^{\ddagger}$ Hayleigh Kearns, ${ }^{\#}$ Hani El Moll, ${ }^{\dagger, \|}$ Karen Faulds, ${ }^{\#}$ \\ Joseph A. Wright, ${ }^{\dagger}$ Bruce S. Brunschwig, ${ }^{\S}$ Koen Clays, ${ }^{\ddagger}$ and John Fielden* ${ }^{*} \uparrow \odot$ \\ ${ }^{\dagger}$ School of Chemistry, University of East Anglia, Norwich, NR4 7TJ, United Kingdom \\ ${ }^{\ddagger}$ Department of Chemistry, University of Leuven, Celestijnenlaan 200D, B-3001 Leuven, Belgium \\ ${ }^{\S}$ Beckman Institute, California Institute of Technology, 1200 East California Blvd., MC 139-74, Pasadena, California 91125, United \\ States \\ ${ }^{\#}$ Department of Pure and Applied Chemistry, University of Strathclyde, 99 George Street, Glasgow, G1 1RD, United Kingdom \\ ${ }^{\nabla}$ College of Pharmacy, University of Kerbala, Kerbala, Iraq
}

\section{Supporting Information}

\begin{abstract}
Ten organoimido polyoxometalate (POM)-based chromophores have been synthesized and studied by hyper-Rayleigh scattering (HRS), Stark and Resonance Raman spectroscopies, and density functional theory (DFT) calculations. HRS $\beta_{0}$ values for chromophores with resonance electron donors are significant (up to $139 \times 10^{-30}$ esu, $\sim 5$ times greater than that of the DAS ${ }^{+}$cation), but systems with no donor, or the $-\mathrm{NO}_{2}$ acceptor show no activity, in some cases, despite large DFT-predicted $\beta$-values. In active systems with short (phenyl) $\pi$-bridges, $\beta_{0}$ values comfortably exceed that of the purely organic structural analogue $N, N$-dimethyl-4-nitroaniline (DMPNA), and intrinsic $\beta$-values, $\beta_{0} / \mathrm{N}^{3 / 2}$ (where $N$ is the number of bridge $\pi$-electrons) thus appear to break empirical performance limits $\left(\beta_{0} / \mathrm{N}^{3 / 2}\right.$ vs $\left.\lambda_{\text {max }}\right)$ for planar organic systems. However, $\beta_{0}$ values

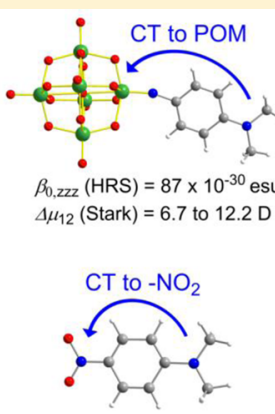

$\beta_{0, z z z}(\mathrm{HRS})=33 \times 10^{-30} \mathrm{esu}$ $\Delta \mu_{12}($ Stark $)=7.3$ to $8.1 \mathrm{D}$

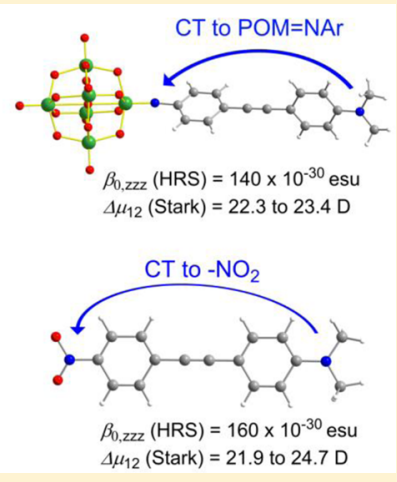
obtained for extended systems with a diphenylacetylene bridge are comparable to or lower than that of their nitro analogue, N,N-dimethyl-4-[(4-nitrophenyl)ethynyl]-aniline (DMNPEA). Resonance Raman spectroscopy confirms the involvement of the POM in the electronic transitions, whether donor groups are present or not, but Stark spectroscopy indicates that, in their absence, the transitions have little dipolar character (hence, NLO inactive), consistent with DFT-calculated frontier orbitals, which extend over both POM and organic group. Stark and DFT also suggest that $\beta$ is enhanced in the short compounds because the extension of charge transfer (CT) onto the POM increases changes in the excited-state dipole moment. With extended $\pi$-systems, this effect does not increase CT distances, relative to a $-\mathrm{NO}_{2}$ acceptor, so $\beta_{0}$ values do not exceed that of DMNPEA. Overall, our results show that (i) the organoimido-POM unit is an efficient acceptor for second-order NLO, but an ineffective donor; (ii) the nature of electronic transitions in arylimido-POMs is strongly influenced by the substituents of the aryl group; and (iii) organoimido-POMs outperform organic acceptors with short $\pi$-bridges, but lose their advantage with extended $\pi$-conjugation.
\end{abstract}

\section{INTRODUCTION}

Polyoxometalates (POMs) are a class of anionic, molecular metal oxide clusters, whose range of properties is commensurate with their enormous variety of structural types. ${ }^{1}$ POMs can be derivatized with organic groups, and recent years have seen great advances in the synthetic chemistry of such POM "hybrids"-both in terms of initial derivatization of the POM, and a range of organic transformations that can be used to postfunctionalize the resulting hybrid. ${ }^{2}$ These have allowed the construction of POM-organic architectures of increasing complexity, including polymers ${ }^{3}$ and POMs linked to catalytic centers ${ }^{4}$ or light-harvesting chromophores. ${ }^{5,6}$ Such research is motivated by the promise of emergent or synergic properties resulting from the combination of the organic and inorganic components. For example, connection of lacunary Keggin $\left(\mathrm{XW}_{11} \mathrm{O}_{39}{ }^{n-}\right)$ or Dawson $\left(\mathrm{X}_{2} \mathrm{~W}_{17} \mathrm{O}_{61}{ }^{n-}\right)$ POMs to organic or metallo-organic chromophores ${ }^{5-7}$ can create systems where photoexcitation of the chromophore leads to multiple charge accumulation on the electron accepting $\mathrm{POM}^{6 c, 7}$ and reduction of protons to dihydrogen. ${ }^{7}$ However, electronic isolation of the POM from the organic subunits means that these properties are an enhancement (due to enforced spatial proximity) of behavior that occurs with unconnected POMs and chromophores. Instead, we are interested in studying new optical and

Received: March 22, 2017

Published: August 15, 2017 
photophysical behaviors that emerge when strong electronic coupling occurs between POMs and appended organic groups.

Organoimido POM derivatives-typically of the Lindqvist family $\left(\left[\mathrm{M}_{6} \mathrm{O}_{19}\right]^{2-}\right.$, where $\left.\mathrm{M}=\mathrm{Mo}, \mathrm{W}\right)$-demonstrate this strong electronic coupling through new electronic transitions and shifted POM reduction potentials. ${ }^{8}$ Their synthetic chemistry is well-developed, and many species can be accessed through a DCC-mediated amine/POM coupling, , $^{2,9}$ followed by various organic post-functionalizations. However, the photonic properties of these materials have so far been addressed only slightly, beyond calculations ${ }^{10}$ suggesting second-order nonlinear optical coefficients (first hyperpolarizability, $\beta>10^{-27}$ esu in some cases) that compete with highperformance organic materials, ${ }^{11}$ but surprisingly seem to be based on POM-to-nitro CT. Given the relatively high energies of organoimido-POM electronic transitions, and the challenge of obtaining high-activity molecular nonlinear optical (NLO) materials with adequate transparency (reabsorption of visible light can cause lowered efficiency, overheating and instability), this has encouraged us to explore the arylimido Lindqvist anion as a platform for new high-activity, high-transparency secondorder NLO materials. Such materials are of potential value to technologies in telecommunications and optical/electro-optical computing, ${ }^{12}$ but current approaches generally rely on multidimensional chromophores that can be synthetically complex, and/or involve use of precious metals (e.g., $\mathrm{Ru}$ ) to provide an octupolar core. ${ }^{13}$

We recently found that a small family of arylimido polyoxometalate derivatives have experimentally determined (by hyper-Rayleigh Scattering, HRS) static, resonance corrected $\beta_{0}$ values of up to $133 \times 10^{-30}$ esu. $^{14}$ This compares to $25 \times 10^{-30}$ esu for technologically valuable $\mathrm{DAS}^{+}$under nonresonant conditions, and in some cases the POM-based chromophores break through empirical NLO performance limits for planar organics, ${ }^{15}$ as defined by electron-number adjusted $\beta$ versus the absorption wavelength $\lambda_{\max }$. Therefore, organoimido POMs are among a small group of dipolar chromophores, comprising "tictoid" compounds with twisted $\pi$ bridges $^{16}$ and other systems with highly unusual donor sets, ${ }^{17}$ that have been seen to exceed these limits, but are the only to do so with conventional planar $\pi$-bridges and donor groups (e.g, $-\mathrm{NR}_{2},-\mathrm{OR}, \mathrm{O}^{-}$). As such, they may offer a low-cost, convenient route to high-performance, high-transparency NLO materials. Herein, we expand the series of organoimido-POM chromophores, establishing structure-activity relationships, and use Resonance Raman and Stark spectroscopies, and density functional theory (DFT) calculations to elucidate the nature of the charge-transfer transitions responsible for their NLO properties. These show that the derivatives lack dipolar character (and are hence NLO inactive) in the absence of resonance electron donors. However, with suitable resonance donors and short $\pi$-bridges, the imido-POM acceptors enhance NLO activity versus organic analogues by extending charge transfer onto the POM, increasing dipole moment changes.

\section{EXPERIMENTAL SECTION}

Synthesis, Characterization, and DFT Calculations. Details pertaining to synthetic chemistry and standard chemical and physical characterization (NMR spectroscopy, X-ray crystallography, etc.), and DFT calculations can be found in the Supporting Information (SI).

Raman Spectroscopy. The POM derivatives were prepared as 5 $\mathrm{mM}$ solutions in acetonitrile. Samples were analyzed in glass cuvettes using $600 \mu \mathrm{L}$ of the solution. Raman measurements were performed using Snowy Range (SnRI) portable Raman spectrometers. Two excitation sources were used: a diode laser with $532 \mathrm{~nm}$ excitation (50 $\mathrm{mW}$ of power) and a diode laser with $785 \mathrm{~nm}$ excitation $(100 \mathrm{~mW})$. Acquisition times were $0.2 \mathrm{~s}$ at $532 \mathrm{~nm}$ and $1 \mathrm{~s}$ at $785 \mathrm{~nm}$. The SnRI $532 \mathrm{~nm}$ spectrometer has a wavenumber range from $200 \mathrm{~cm}^{-1}$ to 3200 $\mathrm{cm}^{-1}$, whereas the $785 \mathrm{~nm}$ spectrometer has a range from $200 \mathrm{~cm}^{-1}$ to $2000 \mathrm{~cm}^{-1}$. The Raman measurements were normalized to a cyclohexane standard, with respect to the peak at $801 \mathrm{~cm}^{-1}$. Spectra were baseline-corrected using a multipoint linear fit and a level and zero-leveling mode in Grams software (AI 7.0).

Hyper-Rayleigh Scattering. General details of the hyper-Rayleigh scattering (HRS) experiment have been discussed elsewhere, ${ }^{18}$ as have been the experimental procedure and data analysis protocol used for the fs measurements in this study. ${ }^{19}$ Measurements were carried out using dilute $\left(\mathrm{ca} .10^{-5} \mathrm{M}\right.$ ) filtered (Millipore, $0.45 \mu \mathrm{m}$ ) acetonitrile solutions, so that self-absorption of the SHG signal was negligible, verified by the linear relation between signal and concentration. Crystal violet was used as an external reference $\left(\beta_{x x x, 800}=338 \times 10^{-30}\right.$ esu in methanol, ${ }^{19 a}$ corrected for local field factors at optical frequencies). All $800 \mathrm{~nm}$ measurements were performed using the $800 \mathrm{~nm}$ fundamental of a regenerative mode-locked $\mathrm{Ti}^{3+}$ :sapphire laser (Spectra Physics, model Tsunami, 100 fs pulses, $2 \mathrm{~W}, 80 \mathrm{MHz}$ ). An absence of demodulation for most compounds, i.e., constant values of $\beta$ versus frequency, showed that no multiphoton fluorescence contributions to the HRS signals were present at $400 \mathrm{~nm}$. This may indicate (i) a lack of fluorescence, (ii) spectral filtering out of fluorescence, or (iii) the fluorescence lifetime is too short for its demodulation to be observed within the bandwidth of the instrument. Where present, fluorescence has been corrected by demodulation fitting to provide a fluorescence free value of $\beta$. The reported $\beta$ values are the averages taken from measurements at different amplitude modulation frequencies. Measurements at $1064 \mathrm{~nm}$ were carried out in acetonitrile, using a Spectra-Physics InSight DS+ laser (average power of $1 \mathrm{~W}$, sub-100 fs pulses, $80 \mathrm{MHz}$ ). In this setup, the collection optics are coupled to a spectrograph (Bruker, Model 500is/sm) and an EMCCD camera (Andor Solis model iXon Ultra 897). Correction for multiphoton-induced fluorescence was done by subtracting the broad MPF background signal from the narrow HRS peak ( fwhm $= \pm 9 \mathrm{~nm}$ ). The higher accuracy of this setup enables us to use the solvent as an internal reference (acetonitrile, $\beta_{\mathrm{HRS}, 1064}=0.258 \times 10^{-30} \mathrm{esu} ; \beta_{z z z, 1064}=$ $\left.0.623 \times 10^{-30} \mathrm{esu}\right) .^{20}$

Stark Spectroscopy. Stark spectra were collected in butyronitrile glasses at $77 \mathrm{~K}$ (estimated local field correction $f_{\text {int }}=1.33$ ). Apparatus and data collection procedure were as previously reported, ${ }^{21}$ but with a $\mathrm{Xe}$ arc lamp as the light source in place of a tungsten filament bulb. Each spectrum was measured at least twice, and spectra were modeled with a sum of two or three Gaussian curves that reproduce the band of interest. The second, first, and zeroth derivatives of the Gaussian curves were then used to fit the Stark spectra with Liptay's equation. ${ }^{22}$ The dipole moment change $\left(\Delta \mu_{12}=\mu_{\mathrm{e}}-\mu_{\mathrm{g}}\right.$, where $\mu_{\mathrm{e}}$ and $\mu_{\mathrm{g}}$ are the respective excited- and ground-state dipole moments) was then calculated from the coefficient of the second derivative component. This assumes that the two-state model is applicable to the systems investigated here, which have relatively high transition energies, and may be complicated from mixing with other states close in energy. Thus, values obtained for the compounds with the highest energy absorption bands in this series are subject to additional uncertainty. The following equations and definitions are integral to the subsequent discussion:

A two-state analysis of the ICT transitions gives

$$
\Delta \mu_{\mathrm{ab}}{ }^{2}=\Delta \mu_{12}{ }^{2}+4 \mu_{12}{ }^{2}
$$

where $\Delta \mu_{\mathrm{ab}}$ is the dipole moment change between the diabatic states, $\Delta \mu_{12}$ is the observed (adiabatic) dipole moment change, and $\mu_{12}$ is the transition dipole. ${ }^{21}$ The value of $\mu_{12}$ can be determined from the oscillator strength $f_{\text {os }}$ of the transition, using the relation

$$
\left|\mu_{12}\right|=\left(\frac{f_{\text {os }}}{1.08 \times 10^{-5} E_{\max }}\right)^{1 / 2}
$$


where $E_{\max }$ is the energy of the ICT maximum (in wavenumbers) and $\mu_{12}$ is given in eA. The latter is converted to Debye units upon multiplying by 4.803 . The degree of delocalization ${c_{\mathrm{b}}}^{2}$ and electronic coupling matrix element $H_{\mathrm{ab}}$ for the diabatic states are given by

$$
\begin{aligned}
& \left|H_{\mathrm{ab}}\right|=\left|\frac{E_{\max }\left(\mu_{12}\right)}{\Delta \mu_{\mathrm{ab}}}\right| \\
& c_{\mathrm{b}}{ }^{2}=\frac{1}{2}\left[1-\left(\frac{\Delta \mu_{12}^{2}}{\Delta \mu_{12}{ }^{2}+4 \mu_{12}{ }^{2}}\right)^{1 / 2}\right]
\end{aligned}
$$

If the hyperpolarizability tensor $\beta_{0}$ has only nonzero elements along the ICT direction, then this quantity is given by

$$
\beta_{0}=\frac{3 \Delta \mu_{12}\left(\mu_{12}\right)^{2}}{\left(E_{\max }\right)^{2}}
$$

The Gaussian fitting procedure used for the Stark spectra is dependent on a variety of parameters as well as the choice of baseline. Thus, while the precision of calculated $\beta_{0}$ values is ca. $20 \%$, given a consistent fitting approach, the actual error of the fitted parameters versus their true values is difficult to estimate, and likely larger. The experimental errors for $\mu_{12}$ and $\Delta \mu_{12}$ are estimated to be $\pm 20 \%$ when the second derivative component dominates the fit, and significantly larger when it does not. Errors for $\Delta \mu_{\mathrm{ab}}, H_{\mathrm{ab}}$, and $c_{\mathrm{b}}{ }^{2}$ are estimated as $\pm 30 \%, \pm 30 \%$, and $\pm 50 \%$, respectively.

\section{RESULTS AND DISCUSSION}

Chromophore Design and Synthesis. To investigate the effects of donor/acceptor substituents and $\pi$-conjugation on the NLO properties of arylimido-Lindqvist species, we synthesized the family of anionic chromophores 1-10 (see Chart 1) as tetrabutylammonium salts.

Chart 1. Polyoxometalate-Based Chromophores and Nitro Analogues Investigated in This Study

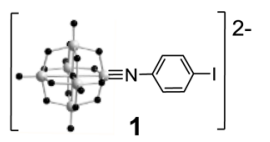

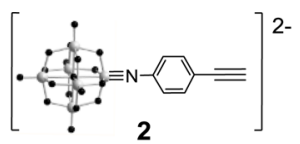

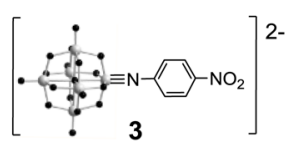

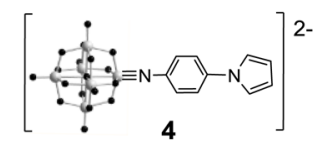

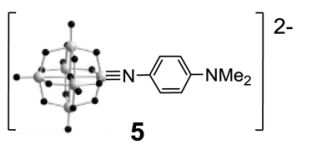

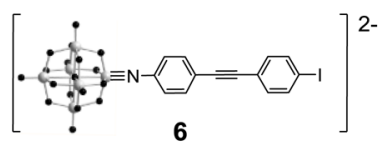

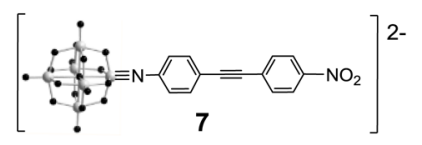

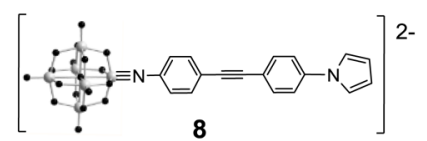

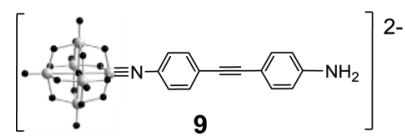

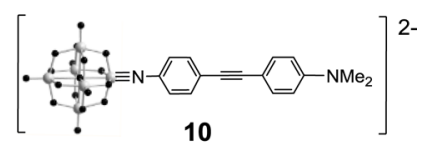

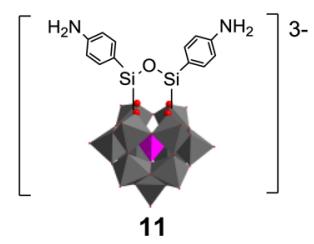

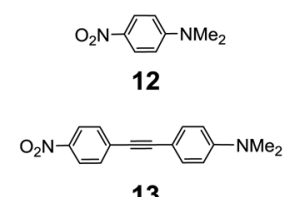

Structures have been elucidated by NMR and electrospray mass spectrometry, supported by elemental analysis and, in most cases, X-ray crystal structures. The organosilyl Keggin anion (11) provides a counterpoint to the imido-Lindqvist species, because it has a strong $-\mathrm{NH}_{2}$ donor but much weaker electronic communication across the $\mathrm{C}-\mathrm{Si}-\mathrm{O}-\mathrm{W}$ bridge, while compounds 12 and 13 provide the closest possible purely organic analogues to the POM derivatives. The synthetic approach to the organo-imido compounds was centered on the $N, N^{\prime}$-dicyclohexylcarbodiimide (DCC) mediated coupling of anilines with $\left[\mathrm{NBu}_{4}\right]_{2}\left[\mathrm{Mo}_{6} \mathrm{O}_{19}\right]$, to produce arylimido Lindqvist derivatives. $^{8,9,14}$ Notably, we found that (i) anhydrous dimethylsulfoxide (DMSO) was a better solvent for this chemistry than the commonly used acetonitrile, and (ii) careful control of temperature and a slight excess of hexamolybdate helped to prevent the formation of undesired (and difficult to separate) bis-imido products. Short chromophores 1-5 were thus accessed by reacting the parent amine with hexamolybdate. Of the extended systems, $\mathbf{6}$ and $\mathbf{8}$ were obtained by direct reaction of hexamolybdate with the parent ligand, while 7,9 , and 10 employed a Sonogashira coupling between 1 and the appropriate alkyne.

NMR Spectroscopy. ${ }^{1} \mathrm{H}$ NMR spectroscopy is an effective tool for primary characterization of (diamagnetic) arylimidohexamolybdates. Compared to the parent anilines, the chemical shifts for the protons ortho- to the imido bonds are shifted downfield by up to $1 \mathrm{ppm}$. This indicates the electronwithdrawing effect that the POM cluster has on the attached aryl group, and is illustrated for compound $\mathbf{4}$ in Figure 1.

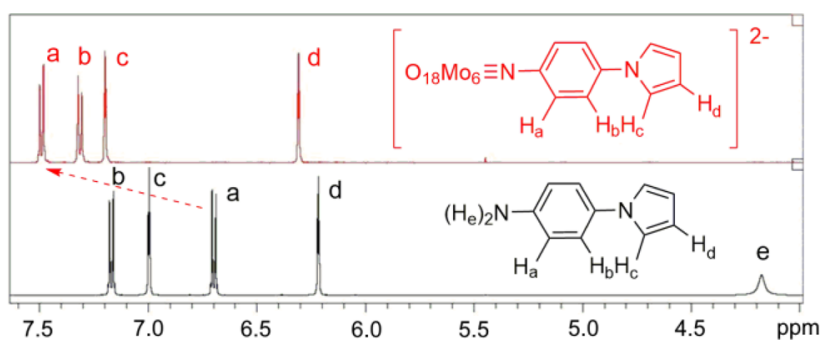

Figure 1. ${ }^{1} \mathrm{H}$ NMR spectrum of the aromatic region of 4, and its amino precursor showing the downfield shift of the ortho- aromatic resonances upon formation of the imido-Lindqvist group.

Chemical shifts for the protons of the 10 imido-Lindqvist derivatives are presented in Table 1. Generally, and logically, the chemical shifts of the protons $\mathrm{H}_{\mathrm{a}}$ ortho to the imido group shift upfield as the donor strength of the D/A substituent increases-decreasing from $7.49 \mathrm{ppm}$ to $7.15 \mathrm{ppm}$ and from $7.62 \mathrm{ppm}$ to $7.46 \mathrm{ppm}$ in the short and long pyrrole/ $\mathrm{NMe}_{2}$ pairs $4 / 5$ and $8 / 9$. Other resonances mostly follow this pattern, most notably $\mathrm{H}_{\mathrm{d}}$ (ortho to the $\mathrm{D} / \mathrm{A}$ group), although not completely consistently-perhaps due to variation in the strength of conjugation and/or ring current effects between the different species. In $-\mathrm{NO}_{2}$ derivatives 3 and 7 , the highest $\delta$ (ca. $8.2 \mathrm{ppm}$ ) is assigned to $\mathrm{H}_{\mathrm{d}}$, consistent with the high $\delta$ observed in organic nitro compounds, yet $\mathrm{H}_{\mathrm{a}}$ shifts upfield, compared to all but 5 (short $-\mathrm{NMe}_{2}$ ), suggesting that the strong $-\mathrm{NO}_{2}$ acceptor may pull electron density from the imido-Lindqvist unit to result in increased shielding of $\mathrm{H}_{\mathrm{a}}$. This is consistent with DFT calculations ${ }^{10}$ (including our own, vide infra) suggesting that, in nitro-substituted organoimidohexamolybdates, the overall direction of charge transfer is 
Table 1. Selected ${ }^{1} \mathrm{H}$ NMR Chemical Shifts ${ }^{a}$ for $1-10$

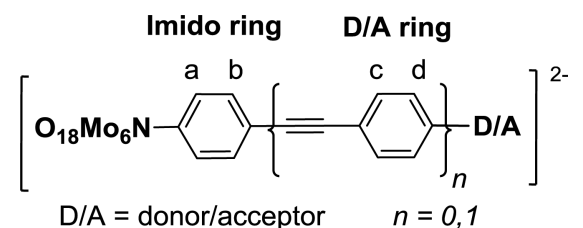

\begin{tabular}{|c|c|c|c|c|c|c|}
\hline & \multicolumn{6}{|c|}{ Chemical Shift, $\delta$ (ppm) } \\
\hline & \multicolumn{2}{|c|}{ Imido Ring } & \multicolumn{2}{|c|}{$\begin{array}{c}\text { Donor/Acceptor } \\
\text { Ring }\end{array}$} & \multirow{2}{*}{\multicolumn{2}{|c|}{$\begin{array}{c}\mathrm{NMe}_{2}, \text { pyrrole, or } \\
\mathrm{NPh}_{2}\end{array}$}} \\
\hline & a & $\mathrm{b}$ & c & d & & \\
\hline $1^{b}$ & 7.75 & 6.99 & & & & \\
\hline $2^{b}$ & 7.49 & 7.19 & & & & \\
\hline $3^{b}$ & 7.34 & 8.22 & & & & \\
\hline $4^{b}$ & 7.49 & 7.32 & & & 7.20 & 6.31 \\
\hline $5^{b}$ & 7.15 & 6.63 & & & 3.07 & \\
\hline 6 & 7.78 & 7.55 & 7.31 & 7.23 & & \\
\hline 7 & 7.61 & 7.26 & 7.75 & 8.24 & & \\
\hline 8 & 7.62 & 7.52 & 7.55 & $7.25^{c}$ & 7.23 & 6.33 \\
\hline 9 & 7.46 & 7.20 & 7.26 & 6.63 & & \\
\hline 10 & 7.46 & 7.20 & 7.37 & 6.72 & 2.98 & \\
\hline
\end{tabular}

${ }^{a}$ Recorded at 300 or $500 \mathrm{MHz}$ in $\mathrm{CD}_{3} \mathrm{CN}$; all $\delta$ are given in ppm with respect to TMS. ${ }^{b} n=0$. ${ }^{c}$ Overlapped with pyrrole signals. Where possible, assignments have been confirmed using two-dimensional (2D) NMR techniques.

from the POM/imido group and to the nitro group, although it does not necessarily indicate that the POM is an effective donor, as proposed elsewhere. ${ }^{10 c, d}$

X-ray Crystal Structures. We have obtained high-quality $\mathrm{X}$-ray crystal structures for all of the organoimido compounds in the study, with the exception of 3 , which failed to produce diffraction-quality crystals. Our structures of 4, 8, and 9 were previously published, ${ }^{14}$ those of the other anions, including $\mathbf{5},{ }^{23}$ are displayed in Figure 2. Full details are presented in the SI.

The Mo-O bond lengths of the imido-hexamolybdate clusters show a similar pattern of lengthening and shortening versus $\left[\mathrm{Mo}_{6} \mathrm{O}_{19}\right]^{2-}$ to that previously described (see the SI), while the bond lengths of the organic ligands show trends consistent with the donor-acceptor nature of the derivatives. Moreover, while these structural phenomena do not necessarily occur in solution (where temperature and local electric field are different to the crystal), they are consistent with the solution photophysical and electrochemical properties. In the "short" chromophores 1-5, a pronounced contraction of the phenyl $\mathrm{C}-\mathrm{C}$ bonds between the ortho- and meta- carbons (Table 2, $r_{3}$ ) compared to the other phenyl C-C bonds $\left(r_{2} / r_{4}\right)$, is observed on moving from $-\mathrm{I}$ and alkynyl derivatives $\mathbf{1}$ and 2 , to the strong donor $-\mathrm{NMe}_{2}$ in $\mathbf{5}$. This is consistent with a significant contribution from a quinoidal resonance form when a strong donor group is present. Further evidence of this is seen in a shortened donor- $\mathrm{N}$ to phenyl bond length in $\mathbf{5}$, compared to the weak pyrrole donor system 4. However, there is no significant change in the $\mathrm{C}-\mathrm{N}$ and $\mathrm{N}-\mathrm{Mo}$ imido bond distances.

This shortening of the ortho-to-meta $\mathrm{C}-\mathrm{C}$ bonds $\left(r_{3}\right)$ is far less pronounced in the extended analogue (10), only statistically significant on the donor ring, and absent in the other extended systems. This implies, logically, that communication between organic donor and POM is weaker with the longer bridge. Moreover, while the acceptor/weak donor
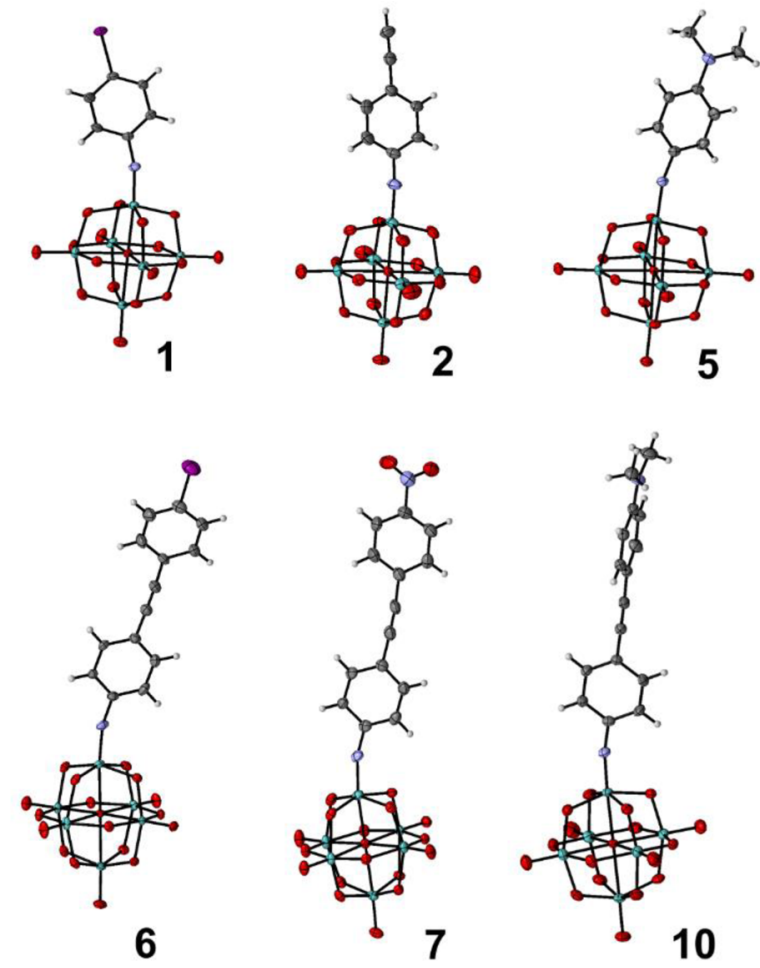

Figure 2. Crystal structures of new chromophoric anions obtained in this study, labeled with the appropriate compound number. [Legend: $\mathrm{C}$, gray; N, blue; $\mathrm{O}$, red; Mo, green; and I, purple. $\mathrm{H}$ atoms are white circles with arbitrary radii.] Disordered parts have been omitted for the sake of clarity. Thermal ellipsoids are at the $30 \%$ probability level.

Table 2. Selected Bond Lengths in Compounds 1-5

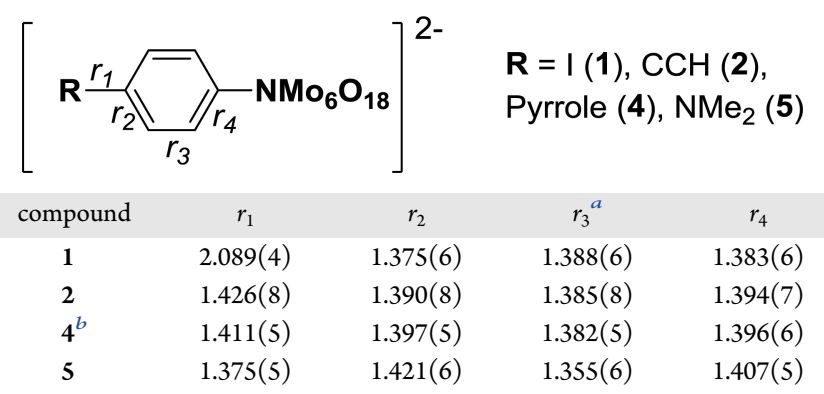

${ }^{a}$ Average of two chemically identical, crystallographically independent $\mathrm{C}-\mathrm{C}$ bonds. ${ }^{b}$ Average of two crystallographically independent anions.

functionalized compounds 6-8 show a coplanar arrangement of the two phenyl rings; $45^{\circ}$ and $86^{\circ}$ twists are observed with the strong $\mathrm{NH}_{2}$ and $\mathrm{NMe}_{2}$ donors. Since the barriers to rotation in unhindered phenylacetylenes are very low (ca. $1 \mathrm{kcal}$ $\left.\mathrm{mol}^{-1}\right),{ }^{24}$ both twisted and coplanar arrangements are often observed in their crystal structures. Even so, the observed twists fit with NMR (vide supra), electrochemical, and Stark spectroscopic measurements (vide infra), suggesting that conjugation across the phenylacetylene unit is weaker with the stronger donors. Such weakened conjugation would further reduce the barrier to rotation and increase the probability of isolating a twisted geometry in the crystal.

Electronic Spectroscopy and Electrochemistry. Connection of arylimido groups to $\left[\mathrm{Mo}_{6} \mathrm{O}_{19}\right]^{2-}$ produces a new transition red-shifted from the $\mathrm{O} \rightarrow$ Mo bands, and also not present in the parent amines. Previously, we tentatively assigned this low energy (LE) band as ligand-to-POM charge 
transfer (LPCT). ${ }^{14}$ This was consistent with our data, and previous descriptions as a ligand-to-metal CT transition redshifted by conjugation of the imido and aryl $\pi$-systems. ${ }^{2 c, 8,9}$ However, the possibility that other electronic transitions contribute to the bands, for example, $\pi-\pi^{*}$ transitions lowered in energy by interaction with the POM, or imido-to-aryl CT transitions (particularly with acceptor groups) ${ }^{10}$ cannot be discounted. Indeed, the LE band red-shifts upon replacement of $-\mathrm{I}$ or $-\mathrm{CCH}$ with the strong resonance acceptor $-\mathrm{NO}_{2}$, showing that $\mathrm{CT}$ is not exclusively to the POM and mandating use of the more general assignment "intra-hybrid charge transfer” (IHCT). Other data (Stark spectroscopy, DFT, Raman spectroscopy) also suggest multiple origins for the LE absorptions (vide infra).

The IHCT bands certainly show LPCT character, demonstrated by the red-shift in $\lambda_{\max }$ with increased donor strength (i.e., from 4 to 5 or from 8 to 10; see Figure 3 and Table 3).

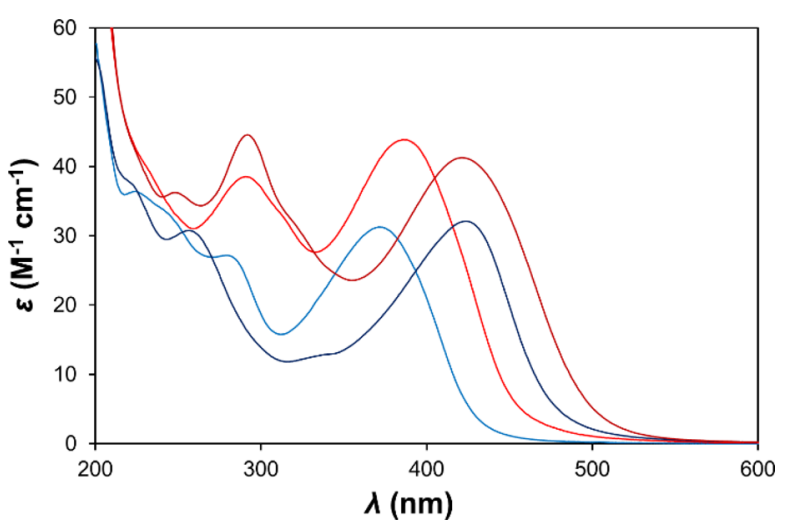

Figure 3. Electronic absorption spectra of 4 (blue), 5 (dark blue), 8 (red), and 10 (deep red) in acetonitrile at $298 \mathrm{~K}$.

Red-shift also occurs with extended conjugation, except for the $-\mathrm{NMe}_{2}$ derivatives 5 and 10: remarkably, 5 has $\lambda_{\max } 3 \mathrm{~nm}$ to the red of the $421 \mathrm{~nm}$ obtained for extended system 10, and also shows a slight change in band shape. This is consistent with X-ray crystallographic evidence for weakened conjugation in extended chromophores with strong donors (vide supra), and particularly strong donor-POM communication in $\mathbf{5}$. Electrochemistry also indicates that donor-POM and acceptor-POM communication is strong in the short chromophores, but weakens in extended systems. Short chromophores 1-5 show a strong dependence in reduction potential upon the group para- to the imido- $\mathrm{N}$, following the expected order of donor strength $\mathrm{NO}_{2}<\mathrm{I}<\mathrm{CCH}<\mathrm{Py}<\mathrm{NMe}_{2}$ across a range of $>140 \mathrm{mV}$. However, the reduction potentials of the five extended systems cover a range of only $27 \mathrm{mV}$, and show no dependence on the organic moiety's donor or acceptor characteristics. Thus, ${ }^{1} \mathrm{H}$ NMR, X-ray crystal structures, electron spectroscopy, and electrochemistry all suggest that $\pi$ conjugation is weakened in extended systems with strong donors.

Hyper-Rayleigh Scattering. Table 4 shows $\beta_{z z z}$ values obtained at $800 \mathrm{~nm}$, and $\beta_{z z z}$ and $\beta_{0}$ values obtained at $1064 \mathrm{~nm}$ for 1-13. The $1064 \mathrm{~nm}$ source was used to obtain the static, resonance-corrected $\beta_{0}$ values, because $\lambda_{\max }$ for all of the chromophores is distant (in all cases, $>100 \mathrm{~nm}$ shorter than the $532 \mathrm{~nm}$ second harmonic), and residual absorption is minimal at this wavelength. At $800 \mathrm{~nm}, \beta_{0}$ would be severely underestimated, because of the close proximity of $\lambda_{\max }$ to the second harmonic. In addition, electron-number adjusted $\beta$ values, $\beta_{0} / N^{3 / 2}$ (where $N$ is the number of $\pi$-conjugated electrons) have been calculated to facilitate comparison of the intrinsic performance of the POM chromophores with organic materials.

The data indicate that without a resonance electron donor, POM-based chromophores are NLO-inactive, as scattered second harmonic ( $\mathrm{SH}$ ) light failed to exceed the solvent background at both wavelengths for iodo derivatives 1 and $\mathbf{6}$, ethynyl derivative 2 , and nitro derivatives 3 and 7 . This dramatically contrasts with computational studies predicting significant $\beta$ values for organoimido systems with no resonance donor, ${ }^{10}$ and indeed finding high activity for nitro-functionalized systems - this activity being ascribed to POM (or imido) to $-\mathrm{NO}_{2}$ charge transfer. Our HRS results, and resonance Raman and Stark spectroscopy (vide infra), suggest that such any such charge transfer must be very weak, because the electron-withdrawing effect of the POM's delocalized, vacant Mo $4 \mathrm{~d}$ orbitals is more significant than the weak electrondonating ability of its oxo-groups. Unsurprisingly, the aminoaryl silyl Keggin derivative (11), which shows little evidence of donor-acceptor communication via electronic spectroscopy or electrochemistry, is also NLO-inactive.

However, all five imido-Lindqvist species with resonance electron donors (short chromophores $\mathbf{4}$ and $\mathbf{5}$, and extended systems 8-10) show significant (large) dynamic $\beta_{z z z}$ values at both measured wavelengths, with the highest values of $813 \times$ $10^{-30}$ esu $(800 \mathrm{~nm})$ and $440 \times 10^{-30}$ esu $(1064 \mathrm{~nm})$ being obtained for 10. $\beta_{z z z}$ values are consistently lower at $1064 \mathrm{~nm}$, most likely because any resonance enhancement is effectively eliminated, but the overall trend in the dynamic first hyperpolarizabilities is similar at the two wavelengths, with extended, dimethylamino donor 10 being the most active, and short, pyrrole donor 4 being the least active. The small differences (relative performance of $\mathbf{5}$ and 8 ) are likely due to uncertainties in the $400 \mathrm{~nm}$ data, relating to resonance contributions, so the $1064 \mathrm{~nm}$ data should be considered more reliable. Notably, the trend in the $1064 \mathrm{~nm}$ data is consistent with established structure activity relationships for organic systems, whereby increased donor strength and conjugation length lead to higher $\beta$.

Static first hyperpolarizabilities, $\beta_{0}$, from the $1064 \mathrm{~nm}$ data facilitate comparison with purely organic chromophores, and reveal that the POM derivatives generally have high activities given their relatively small $\pi$-systems, simple planar structures (alkyne bridges are generally considered less efficient than alkenes in 2nd order $\mathrm{NLO}^{25}$ ), moderate donor strengths and high transition energies. All five active chromophores have $\beta_{0}$ values comfortably exceeding that of the technologically valuable $\mathrm{DAS}^{+}$cation $\left(25 \times 10^{-30}\right.$ esu, $\left.\lambda_{\max }=470 \mathrm{~nm}\right)$, and several more active stilbazolium chromophores, but with significantly less-red-shifted absorption profiles. The most pertinent comparison, however, is with nitro-acceptor-based 12 and 13 since, for both imido-POM and $-\mathrm{NO}_{2}$ the acceptor is based on an N-substituent with a formal positive charge, that can delocalize charge away from the $\pi$-bridge. This shows a large enhancement in $\beta_{0}$ for the POM when a short phenyl spacer is used $\mathbf{- 5}$ is nearly three times more active than its nitro analogue 12, but with the longer phenylacetlyene spacer the performance of POM 10 is lower than (but within experimental error of) its $-\mathrm{NO}_{2}$ analogue 13. Notably, 4, with a weak pyrrole donor, also has higher $\beta_{0}$ values than 12, and both short POM chromophores have very high $\beta_{0} / N^{3 / 2}$ values (3.78 for $4,5.90$ 
Table 3. Electronic Absorption Data and Reduction Potentials $\left(E_{1 / 2}\right)$ for 1-11 and $\left[\mathrm{NBu}_{4}\right]_{2}\left[\mathrm{Mo}_{6} \mathrm{O}_{19}\right]\left(\mathrm{TBAMo}_{6}\right)$

\begin{tabular}{|c|c|c|c|c|c|c|}
\hline & $\lambda_{\max }(\mathrm{nm})^{a}$ & $\varepsilon\left(\times 10^{3} \mathrm{M}^{-1} \mathrm{~cm}^{-1}\right)$ & $E_{\max }(\mathrm{eV})$ & assignment & $E_{1 / 2}(\mathrm{~V})$ & $\Delta E$, vs $\mathrm{Ag} / \mathrm{AgCl}(\mathrm{mV})^{b}$ \\
\hline \multirow[t]{3}{*}{$\mathrm{TBAMo}_{6}$} & 223 & 24.9 & 5.56 & $\mathrm{O} \rightarrow \mathrm{Mo}$ & -0.315 & 69 \\
\hline & 261 & 13.4 & 4.75 & $\mathrm{O} \rightarrow \mathrm{Mo}$ & -0.315 & 69 \\
\hline & 323 & 7.1 & 3.84 & $\mathrm{O} \rightarrow \mathrm{Mo}$ & -0.315 & 69 \\
\hline \multirow[t]{3}{*}{1} & 242 & 37.0 & 5.12 & $\mathrm{O} \rightarrow \mathrm{Mo}$ and $\pi \rightarrow \pi^{*}$ & -0.476 & 63 \\
\hline & 270 & 32.1 & 4.59 & $\mathrm{O} \rightarrow \mathrm{Mo}$ and $\pi \rightarrow \pi^{*}$ & -0.476 & 63 \\
\hline & 355 & 27.0 & 3.49 & $\mathrm{IHCT}$ & -0.476 & 63 \\
\hline \multirow[t]{2}{*}{2} & $264(36.2)$ & & 4.69 & $\mathrm{O} \rightarrow \mathrm{Mo}$ and $\pi \rightarrow \pi^{*}$ & -0.499 & 61 \\
\hline & $358(27.0)$ & & 3.46 & IHCT & -0.499 & 61 \\
\hline \multirow[t]{4}{*}{3} & 216 & 38.3 & 5.74 & $\mathrm{O} \rightarrow \mathrm{Mo}$ and $\pi \rightarrow \pi^{*}$ & -0.434 & 71 \\
\hline & 254 & 26.3 & 4.88 & $\mathrm{O} \rightarrow \mathrm{Mo}$ and $\pi \rightarrow \pi^{*}$ & -0.434 & 71 \\
\hline & 287 & 20.3 & 4.32 & $\mathrm{O} \rightarrow \mathrm{Mo}$ and $\pi \rightarrow \pi^{*}$ & -0.434 & 71 \\
\hline & 371 & 30.2 & 3.35 & IHCT & -0.434 & 71 \\
\hline \multirow[t]{3}{*}{4} & 223 & 39.6 & 5.56 & $\mathrm{O} \rightarrow \mathrm{Mo}$ and $\pi \rightarrow \pi^{*}$ & -0.500 & 63 \\
\hline & 281 & 28.2 & 4.41 & $\mathrm{O} \rightarrow \mathrm{Mo}$ and $\pi \rightarrow \pi^{*}$ & -0.500 & 63 \\
\hline & 371 & 32.3 & 3.34 & IHCT & -0.500 & 63 \\
\hline \multirow[t]{3}{*}{5} & 221 & 37.5 & 5.61 & $\mathrm{O} \rightarrow \mathrm{Mo}$ and $\pi \rightarrow \pi^{*}$ & -0.575 & 71 \\
\hline & 258 & 30.6 & 4.80 & $\mathrm{O} \rightarrow \mathrm{Mo}$ and $\pi \rightarrow \pi^{*}$ & -0.575 & 71 \\
\hline & 424 & 32.0 & 2.92 & IHCT & -0.575 & 71 \\
\hline \multirow[t]{3}{*}{6} & 236 & 31.4 & 5.26 & $\mathrm{O} \rightarrow \mathrm{Mo}$ and $\pi \rightarrow \pi^{*}$ & -0.504 & 69 \\
\hline & 299 & 31.8 & 4.15 & $\mathrm{O} \rightarrow \mathrm{Mo}$ and $\pi \rightarrow \pi^{*}$ & -0.504 & 69 \\
\hline & 381 & 40.0 & 3.25 & IHCT & -0.504 & 69 \\
\hline \multirow[t]{3}{*}{7} & 241 & 36.0 & 5.14 & $\mathrm{O} \rightarrow \mathrm{Mo}$ and $\pi \rightarrow \pi^{*}$ & -0.486 & 64 \\
\hline & 269 & 29.9 & 4.60 & $\mathrm{O} \rightarrow \mathrm{Mo}$ and $\pi \rightarrow \pi^{*}$ & -0.486 & 64 \\
\hline & 389 & 49.6 & 3.18 & $\mathrm{IHCT}$ & -0.486 & 64 \\
\hline \multirow[t]{2}{*}{8} & 290 & 40.1 & 4.28 & $\mathrm{O} \rightarrow \mathrm{Mo}$ and $\pi \rightarrow \pi^{*}$ & -0.496 & 61 \\
\hline & 386 & 43.8 & 3.21 & $\mathrm{IHCT}$ & -0.496 & 61 \\
\hline \multirow[t]{2}{*}{9} & 281 & 39.2 & 4.41 & $\mathrm{O} \rightarrow$ Mo and $\pi \rightarrow \pi^{*}$ & -0.476 & 63 \\
\hline & 406 & 35.8 & 3.05 & IHCT & -0.476 & 63 \\
\hline \multirow[t]{3}{*}{10} & 248 & 36.2 & 5.02 & $\mathrm{O} \rightarrow$ Mo and $\pi \rightarrow \pi^{*}$ & -0.498 & 61 \\
\hline & 292 & 44.5 & 4.24 & $\mathrm{O} \rightarrow \mathrm{Mo}$ and $\pi \rightarrow \pi^{*}$ & -0.498 & 61 \\
\hline & 421 & 41.2 & 2.94 & IHCT & -0.498 & 61 \\
\hline \multirow[t]{2}{*}{11} & 263 & 64.0 & 4.72 & $\mathrm{O} \rightarrow \mathrm{W}$ and $\pi \rightarrow \pi^{*}$ & -0.331 & 69 \\
\hline & 263 & 64.0 & 4.72 & $\mathrm{O} \rightarrow \mathrm{W}$ and $\pi \rightarrow \pi^{*}$ & -0.850 & 71 \\
\hline
\end{tabular}

${ }^{a}$ Concentrations ca. $10^{-5} \mathrm{M}$ in $\mathrm{MeCN} .{ }^{b}$ Solutions ca. $10^{-3} \mathrm{M}$ in analyte and $0.1 \mathrm{M}$ in $\left[\mathrm{NBu}_{4}\right]\left[\mathrm{BF}_{4}\right]$ at a glassy carbon working electrode with a scan rate of $100 \mathrm{mV} \mathrm{s}^{-1}$. Ferrocene internal reference $E_{1 / 2}=0.46 \mathrm{~V}, \Delta E_{\mathrm{p}}=80 \mathrm{mV}$.

for 5) for their modest $\lambda_{\max }$. This places them comfortably beyond the apparent limit described by Kuzyk et al. ${ }^{15}$ for planar organic chromophores (Figure 4), with reference compound $\mathbf{1 2}$ (whose $\beta_{0}$ value agrees well with the previously determined 29 $\times 10^{-30} \mathrm{esu}^{26}$ ) close to the limit. Since the $\beta_{0}$ obtained for $\mathbf{1 3}$ is significantly greater than that previously measured by EFISH $\left(46 \times 10^{-30} \mathrm{esu}\right.$, the benchmark in our previous work $\left.{ }^{14}\right)$, under our conditions this compound together with POMs 9 and $\mathbf{1 0}$ also appears to (just) exceed the apparent limit. While this means comparisons with other studies must be made with caution, and it must be emphasized that POM electrons are not included in $N$; the $\beta_{0} / N^{3 / 2}$ values make it clear that the POM has a large effect on short $\pi$-systems, and only a few other dipolar chromophores exceed the Figure 4 apparent limit as comfortably as $\mathbf{4}$ and $\mathbf{5}$. These typically feature unusual, highly twisted "TICT" $\pi$-systems that favor charge separation (dramatically increasing the contribution of $\Delta \mu_{12}$ in the twostate model). This, and observation of the highest intrinsic $\beta$ in the chromophores with the smallest $\pi$-systems (opposite to the normal trend in purely organic systems such as 12 and 13), indicate that the POM must be playing a significant role in the NLO activity of the phenyl bridged "short" systems. These results raise questions about the nature of the IHCT bands in the HRS active/inactive compounds, and the reason for the unusually high activity of the short POM derivatives versus 
Table 4. HRS Data at 800 and $1064 \mathrm{~nm}$ for 1-13

\begin{tabular}{|c|c|c|c|c|c|}
\hline compound & $\lambda_{\max }(\mathrm{nm})$ & $\beta_{z z z, 800}\left(\times 10^{-30} \mathrm{esu}\right)^{a}$ & $\beta_{z z z, 1064}\left(\times 10^{-30} \mathrm{esu}\right)^{a}$ & $\beta_{0,1064}\left(\times 10^{-30} \mathrm{esu}\right)^{b}$ & $\beta_{0} / N^{3 / 2}$ \\
\hline 1 & 355 & inactive & inactive & & \\
\hline 2 & 358 & inactive & inactive & & \\
\hline 3 & 371 & inactive & inactive & & \\
\hline 4 & 371 & $292 \pm 34$ & $123 \pm 10$ & $56 \pm 5$ & 3.78 \\
\hline 5 & 424 & $302 \pm 58$ & $283 \pm 7$ & $87 \pm 2$ & 5.90 \\
\hline 6 & 381 & inactive & inactive & & \\
\hline 7 & 389 & inactive & inactive & & \\
\hline 8 & 386 & $557 \pm 56$ & $143 \pm 10$ & $59 \pm 5$ & 1.12 \\
\hline 9 & 406 & $716 \pm 63$ & $372 \pm 22$ & $133 \pm 8$ & 2.53 \\
\hline 10 & 421 & $813 \pm 144$ & $440 \pm 55$ & $139 \pm 17$ & 2.65 \\
\hline 11 & 262 & inactive & inactive & & \\
\hline 12 & 394 & not measured & $84 \pm 13$ & $33 \pm 5$ & 2.17 \\
\hline 13 & 406 & not measured & $452 \pm 68$ & $161 \pm 24$ & 3.08 \\
\hline
\end{tabular}

${ }^{a} \beta_{z z z}$ assuming a single dominant tensor component, measured using 800 and $1064 \mathrm{~nm}$ fundamental laser beams. The quoted units (esu) can be converted into SI units $\left(\mathrm{C}^{3} \mathrm{~m}^{3} \mathrm{~J}^{-2}\right)$ by dividing by a factor of $2.693 \times 10^{20} .{ }^{b}$ Nonresonant, static $\beta$ estimated from $\beta_{z z z}$ using the two-state model. ${ }^{22}$

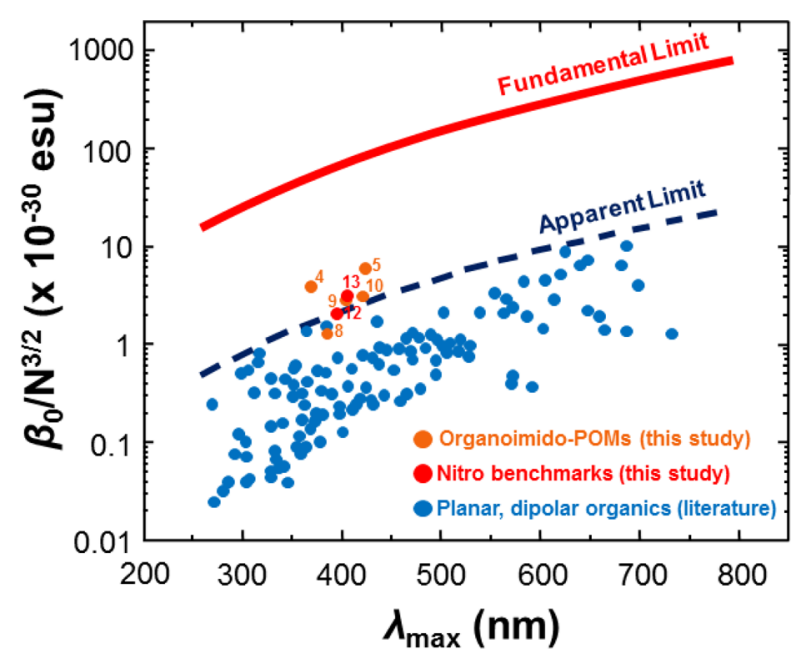

Figure 4. Electron-number-adjusted $\beta$ values $\left(\beta_{0} / N^{3 / 2}\right)$ of NLO-active organoimido-POMs, and a range of planar, dipolar organic chromophores from the literature, plotted against their wavelengths of maximum absorption $\left(\lambda_{\max }\right)$.

comparable organic materials, that we address below in a combined spectroscopic and computational approach.

Raman Spectroscopy. In Resonance Raman spectroscopy, Raman modes of parts of the molecule or assembly associated with an excited transition are enhanced in intensity. ${ }^{27}$ By using one wavelength $(785 \mathrm{~nm})$ far from the absorption of any of the POM derivatives, and one $(532 \mathrm{~nm})$ coinciding with the tail of the absorption, it is therefore possible to test for involvement (but not the role) of the POM. We performed these measurements on a subset of the POM derivatives: 1, 3, 57, and 10, plus $\left[\mathrm{NBu}_{4}\right]_{2}\left[\mathrm{Mo}_{6} \mathrm{O}_{19}\right]$ and nitro analogues 12 and 13.

The results (Figure 5, as well as Figures S7-S9 in the SI) show that, in all of the organoimido-POMs, vibrational modes at ca. $990 \mathrm{~cm}^{-1}$ are enhanced with excitation at $532 \mathrm{~nm}$, vs 785 $\mathrm{nm}$ (where they are almost undetectable). No such effect is observed in $\left[\mathrm{NBu}_{4}\right]_{2}\left[\mathrm{Mo}_{6} \mathrm{O}_{19}\right]$. The enhanced $990 \mathrm{~cm}^{-1}$ band is absent from POM-free 12 and 13, and at similar energy to the symmetric $a_{1 \mathrm{~g}} \mathrm{Mo}=\mathrm{O}$ mode of $\left[\mathrm{Mo}_{6} \mathrm{O}_{19}\right]^{2-}(980-986$ $\left.\mathrm{cm}^{-1}\right),{ }^{28}$ the IR-active $\mathrm{Mo}=\mathrm{NAr}$ stretch of the imido derivatives $^{29}$ ( $\mathrm{ca} .975 \mathrm{~cm}^{-1}$ ), and the $a_{1}$ mode of the reduced anion $\left[\mathrm{Mo}_{6} \mathrm{O}_{19}\right]^{3-}\left(970 \mathrm{~cm}^{-1}\right){ }^{28 a}$ Thus, enhancement of this
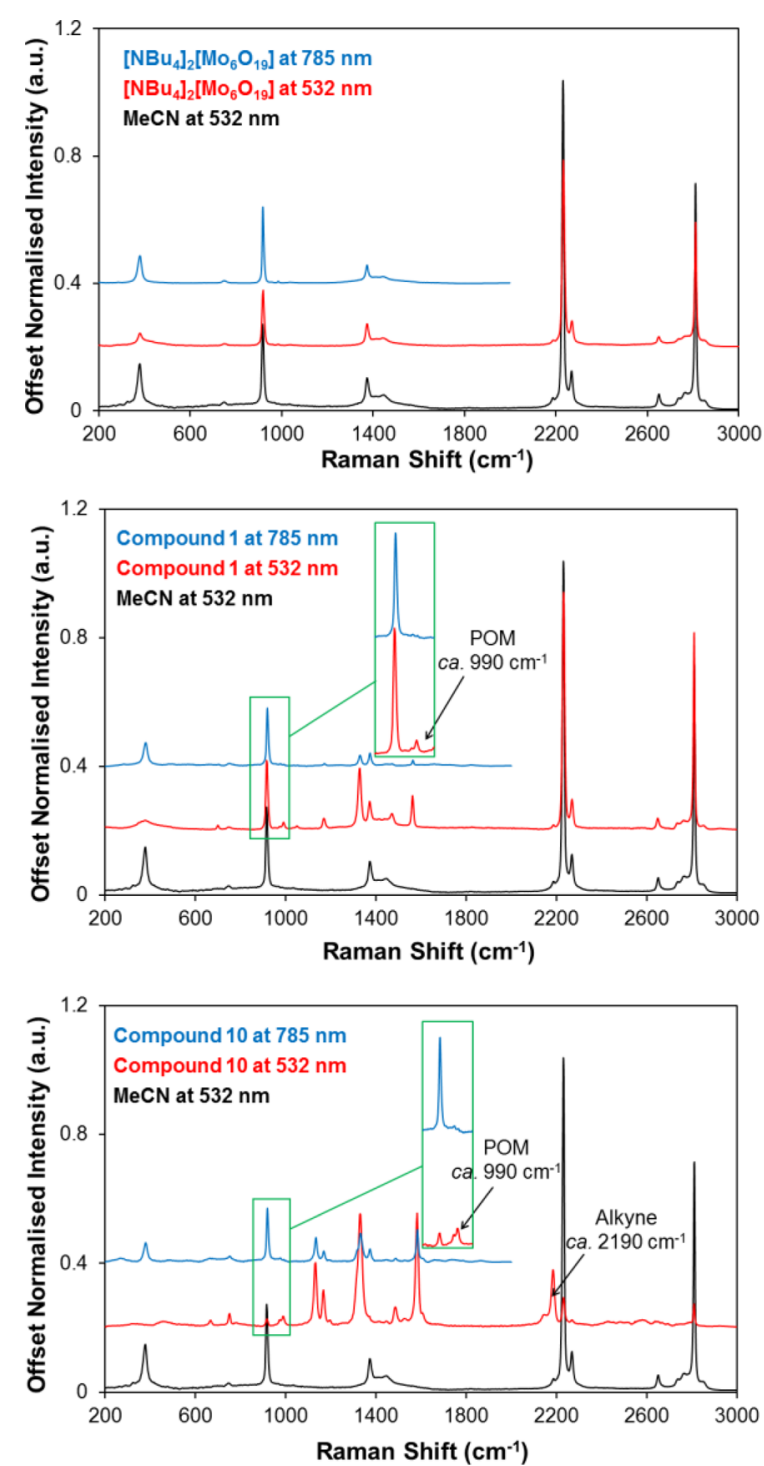

Figure 5. Raman spectra of $\left[\mathrm{NBu}_{4}\right]_{2}\left[\mathrm{Mo}_{6} \mathrm{O}_{19}\right]$ (top), 1 (middle), and 10 (bottom) excited at 532 and $785 \mathrm{~nm}$. Concentration $=5 \mathrm{mM}$.

band with $532 \mathrm{~cm}^{-1}$ excitation implies involvement of the POM and/or imido group in the IHCT transition, in all of the investigated imido-POMs. 
Table 5. ICT Absorption and Stark Spectroscopic Data for 1-10, and Organic Analogues 12 and 13

\begin{tabular}{|c|c|c|c|c|c|c|c|c|c|c|c|c|c|c|}
\hline & $\lambda_{\max }(\mathrm{nm})^{a}$ & $E_{\max }(\mathrm{eV})^{a}$ & $\begin{array}{c}\text { Amp } \\
\text { (norm) }\end{array}$ & $\begin{array}{c}\text { Fwhh } \\
(\mathrm{eV})\end{array}$ & $f_{\mathrm{os}}{ }^{b}$ & $\begin{array}{c}\mu_{12} \\
(\mathrm{D})^{c}\end{array}$ & $\begin{array}{l}\Delta \mu_{12} \\
(\mathrm{D})^{a}\end{array}$ & $\begin{array}{l}\Delta \mu_{\mathrm{ab}} \\
(\mathrm{D})^{e}\end{array}$ & $\begin{array}{l}r_{12} \\
(\AA)^{f}\end{array}$ & $\left(\stackrel{r_{\mathrm{ab}}}{\mathrm{A}}\right)^{g}$ & $\begin{array}{c}H_{\mathrm{ab}}{ }^{h} \\
\left(\times 10^{3} \mathrm{~cm}^{-1}\right)\end{array}$ & $c_{\mathrm{b}}{ }^{2 i}$ & $\begin{array}{c}\beta_{0} \\
\left(\times 10^{-30} \mathrm{esu}\right)^{j}\end{array}$ & $\sum_{\left(\times 10^{-30} \beta_{\text {esu }}\right)^{k}}^{k}$ \\
\hline \multirow[t]{2}{*}{$\mathbf{1}^{l}$} & $357(371)$ & $3.47(3.30)$ & 0.37 & 0.36 & 0.18 & 3.8 & & & & & & & 0 & $0^{m}$ \\
\hline & $(340)$ & $(3.55)$ & 0.63 & 0.52 & 0.50 & 6.1 & & & & & & & 0 & $0^{m}$ \\
\hline \multirow[t]{2}{*}{$2^{l}$} & $361(381)$ & $3.43(3.25)$ & 0.34 & 0.34 & 0.15 & 3.5 & & & & & & & 0 & $0^{m}$ \\
\hline & $(353)$ & $(3.50)$ & 0.66 & 0.50 & 0.46 & 5.9 & & & & & & & 0 & $0^{m}$ \\
\hline \multirow[t]{3}{*}{3} & $371(410)$ & $3.34(3.03)$ & 0.05 & 0.18 & 0.01 & 1.1 & 6.7 & 7.0 & 1.4 & 1.5 & 3.8 & 0.98 & 1 & $35^{m}$ \\
\hline & (387) & $(3.21)$ & 0.40 & 0.37 & 0.25 & 4.7 & 4.5 & 10.4 & 0.9 & 2.2 & 11.7 & 0.72 & 11 & $35^{m}$ \\
\hline & $(356)$ & $(3.49)$ & 0.56 & 0.54 & 0.61 & 6.7 & 5.4 & 14.5 & 1.1 & 3.0 & 13.0 & 0.68 & 23 & $35^{m}$ \\
\hline \multirow[t]{3}{*}{4} & 381 (409) & $3.25(3.03)$ & 0.11 & 0.16 & 0.03 & 1.6 & 6.3 & 7.0 & 1.3 & 1.5 & 5.6 & 0.95 & 2 & 47 \\
\hline & (383) & $(3.24)$ & 0.67 & 0.45 & 0.59 & 6.9 & 7.7 & 15.9 & 1.6 & 3.3 & 11.4 & 0.74 & 41 & 47 \\
\hline & $(347)$ & $(3.58)$ & 0.23 & 0.33 & 0.16 & 3.4 & 3.9 & 7.9 & 0.8 & 1.6 & 12.5 & 0.75 & 4 & 47 \\
\hline \multirow[t]{3}{*}{5} & $438(448)$ & $2.83(2.77)$ & 0.20 & 0.17 & 0.06 & 2.5 & 7.9 & 9.3 & 1.7 & 1.9 & 6.0 & 0.93 & 7 & 86 \\
\hline & (437) & $(2.86)$ & 0.48 & 0.31 & 0.30 & 5.2 & 12.2 & 16.1 & 2.5 & 3.3 & 7.5 & 0.88 & 48 & 86 \\
\hline & $(396)$ & $(3.12)$ & 0.31 & 0.67 & 0.45 & 6.2 & 6.7 & 14.1 & 1.4 & 2.9 & 11.0 & 0.74 & 31 & 86 \\
\hline \multirow[t]{3}{*}{6} & $390(422)$ & $3.18(2.94)$ & 0.14 & 0.14 & 0.06 & 2.3 & 4.2 & 6.3 & 0.9 & 1.3 & 8.8 & 0.84 & 3 & $56^{m}$ \\
\hline & (398) & $(3.12)$ & 0.50 & 0.37 & 0.58 & 7.0 & 5.2 & 14.9 & 1.1 & 3.1 & 11.8 & 0.68 & 31 & $56^{m}$ \\
\hline & $(365)$ & $(3.40)$ & 0.36 & 0.47 & 0.58 & 6.7 & 4.9 & 14.3 & 1.0 & 3.0 & 12.9 & 0.67 & 22 & $56^{m}$ \\
\hline \multirow[t]{3}{*}{7} & $396(426)$ & $3.13(2.91)$ & 0.18 & 0.14 & 0.09 & 2.8 & 4.8 & 7.4 & 1.0 & 1.5 & 9.0 & 0.83 & 5 & $110^{m}$ \\
\hline & (403) & (3.08) & 0.43 & 0.33 & 0.51 & 6.6 & 6.3 & 14.7 & 1.3 & 3.1 & 11.2 & 0.71 & 34 & $110^{m}$ \\
\hline & $(373)$ & $(3.32)$ & 0.39 & 0.52 & 0.79 & 7.9 & 10.4 & 19.0 & 2.2 & 4.0 & 11.2 & 0.78 & 70 & $110^{m}$ \\
\hline \multirow[t]{3}{*}{8} & $400(432)$ & $3.10(2.87)$ & 0.20 & 0.15 & 0.10 & 3.0 & 8.9 & 10.7 & 1.8 & 2.2 & 6.5 & 0.92 & 11 & 130 \\
\hline & (407) & $(3.05)$ & 0.42 & 0.33 & 0.46 & 6.3 & 9.4 & 15.8 & 2.0 & 3.3 & 9.8 & 0.80 & 47 & 130 \\
\hline & $(378)$ & $(3.28)$ & 0.38 & 0.53 & 0.73 & 7.7 & 10.8 & 18.7 & 2.2 & 3.9 & 10.8 & 0.79 & 69 & 130 \\
\hline \multirow[t]{3}{*}{9} & $434(468)$ & $2.86(2.65)$ & 0.23 & 0.18 & 0.10 & 3.2 & 18.8 & 19.8 & 3.9 & 4.1 & 3.4 & 0.97 & 31 & 250 \\
\hline & (442) & $(2.81)$ & 0.41 & 0.31 & 0.33 & 5.5 & 20.7 & 23.4 & 4.3 & 4.9 & 5.3 & 0.94 & 94 & 250 \\
\hline & (413) & $(3.01)$ & 0.36 & 0.47 & 0.47 & 6.4 & 24.0 & 27.2 & 5.0 & 5.7 & 5.7 & 0.94 & 128 & 250 \\
\hline \multirow[t]{3}{*}{10} & $456(482)$ & $2.72(2.57)$ & 0.29 & 0.19 & 0.16 & 4.0 & 22.3 & 23.7 & 4.6 & 4.9 & 3.5 & 0.97 & 64 & 280 \\
\hline & $(456)$ & $(2.72)$ & 0.40 & 0.28 & 0.32 & 5.6 & 23.4 & 26.0 & 4.9 & 5.4 & 4.7 & 0.95 & 116 & 280 \\
\hline & $(427)$ & $(2.90)$ & 0.30 & 0.36 & 0.34 & 5.6 & 23.3 & 25.8 & 4.8 & 5.4 & 5.1 & 0.95 & 99 & 280 \\
\hline \multirow[t]{3}{*}{12} & $408(422)$ & $3.04(2.94)$ & 0.24 & 0.17 & 0.07 & 2.4 & 8.1 & 9.4 & 1.7 & 2.0 & 6.2 & 0.93 & 7 & 42 \\
\hline & (404) & $(3.07)$ & 0.49 & 0.28 & 0.24 & 4.5 & 7.3 & 11.6 & 1.5 & 2.4 & 9.6 & 0.82 & 18 & 42 \\
\hline & $(377)$ & $(3.29)$ & 0.27 & 0.49 & 0.24 & 4.4 & 8.1 & 12.0 & 1.7 & 2.5 & 9.8 & 0.84 & 17 & 42 \\
\hline \multirow[t]{3}{*}{13} & $431(461)$ & $2.88(2.69)$ & 0.16 & 0.26 & 0.07 & 2.7 & 24.7 & 25.3 & 5.1 & 5.3 & 2.3 & 0.99 & 29 & 220 \\
\hline & (434) & $(2.86)$ & 0.49 & 0.38 & 0.34 & 5.6 & 21.9 & 24.6 & 4.6 & 5.1 & 5.3 & 0.95 & 99 & 220 \\
\hline & $(401)$ & (3.09) & 0.35 & 0.58 & 0.40 & 5.9 & 22.2 & 25.1 & 4.6 & 5.2 & 5.8 & 0.94 & 93 & 220 \\
\hline
\end{tabular}

${ }^{a}$ In butyronitrile at $77 \mathrm{~K}$; observed absorption maxima with maxima for Gaussian fitting functions in brackets. Data in all subsequent columns relate to fitted curves. ${ }^{b}$ Obtained from $\left(4.6 \times 10^{-9} \mathrm{M} \mathrm{cm}^{2}\right) \varepsilon_{\max } \times \mathrm{fw}_{1 / 2}$, where $\varepsilon_{\max }$ is the maximal molar extinction coefficient and fw $\mathrm{w}_{1 / 2}$ is the full width at half height (Fwhh, given in $\mathrm{cm}^{-1}$ ). ${ }^{c}$ Calculated using eq $2 .{ }^{d}$ Calculated from $f_{\text {int }} \Delta \mu_{12}$ using $\mathrm{f}_{\text {int }}=1.33$. ${ }^{e}$ Calculated from eq $1 .{ }^{f}$ Delocalized electrontransfer distance calculated from $\Delta \mu_{12} / e{ }^{g}$ Effective (localized) electron-transfer distance calculated from $\Delta \mu_{\mathrm{ab}} / e .{ }^{h} \mathrm{Calculated}$ from eq 3 . $^{i} \mathrm{Calculated}$ from eq $4 .{ }^{j}$ Calculated from eq 5 . ${ }^{k}$ Sum of the $\beta_{0}$ vales from each individual Gaussian function, to 2 sf. ${ }^{l}$ Fitted using only contributions from first and second derivatives; zeroeth derivative contribution set to zero. ${ }^{m}$ Inactive by HRS.

However, there are significant variations in the strength of enhancement between the different organoimido compounds. It is especially strong in $\mathbf{1 0}$ (Figure 5), most likely because this compound has the most significant residual absorption at 532 $\mathrm{nm}$. However, it is weak enough in the other two extended compounds ( 6 and 7), by comparison with short compounds 1 and 3 whose $\lambda_{\max }$ is further from $532 \mathrm{~nm}$, to suggest that involvement of the POM/imido in the transition is weaker (or different) in extended systems that lack a resonance donor. This is consistent with observations by other techniques. The anomaly is $\mathbf{5}$, which, despite the second-largest $532 \mathrm{~nm}$ absorption after 10, a short bridge, and clear evidence for very strong aryl-POM interaction by all other techniques, shows a weak enhancement at $990 \mathrm{~cm}^{-1}$ vs $\mathbf{1 , 3}$, and $\mathbf{1 0}$. It may be that the $990 \mathrm{~cm}^{-1}$ band is more associated with $\mathrm{Mo}=\mathrm{NAr}$ than $\mathrm{Mo}=\mathrm{O}$, and that the extended CT distance for 5 vs nitro- 
analogue 12 (but not for 10 vs 13, vide infra) and its unusually strong red-shift implies the acceptor for CT is more strongly centered on the POM framework for 5 than for 10. As POMs show only minimal structural changes upon reduction, this could cause less vibrational excitation of $\mathrm{Mo}=\mathrm{NAr}$ than an acceptor spread more onto the aryl imido unit. This is consistent with the DFT-calculated lowest energy transitions of $\mathbf{5}$ and $\mathbf{1 0}$ in solution.

In 3 and 7 , the $-\mathrm{NO}_{2}$ group provides an additional probe. Thus, it is significant that organic nitro compounds 12 and 13 show very strong enhancement of the $-\mathrm{NO}_{2}$ band at ca. 855 $\mathrm{cm}^{-1}$ upon moving from $785 \mathrm{~nm}$ to $532 \mathrm{~nm}$, but this effect is much weaker in 3 and 7 (other $\mathrm{ArNO}_{2}$ vibrations ${ }^{30}$ are too close to others observed in $-\mathrm{NO}_{2}$-free systems to be diagnostic). Since 7 has more residual absorption at $532 \mathrm{~nm}$ than 12 (see Figure S10 in the SI), this suggests that the POM/ imido group suppresses $\mathrm{CT}$ to the $\mathrm{NO}_{2}$ group, and most likely vice versa, leading to a weak dipole moment change and the observed HRS inactivity.

Stark Spectroscopy. Stark spectroscopy ${ }^{21,22}$ can measure dipole moment changes and other parameters-e.g., donoracceptor electronic coupling, delocalization-relevant to CT transitions and molecular NLO performance. Moreover, $\beta_{0}$ calculated from Stark data, while yielding values that are often significantly larger than those measured from real SH light (e.g., via HRS or EFISH), ${ }^{10,31}$ generally agree in trend with nonresonant HRS and EFISH. Thus, Stark spectroscopy is a valuable means to assess the relative second-order NLO performance of a group of related chromophores in an experiment that is not complicated by resonance enhancement or reabsorption of $\mathrm{SH}$ light. ${ }^{13 \mathrm{e}}$ Therefore, we use Stark spectroscopy as a complementary technique to understand the IHCT transitions and confirm trends in $\beta_{0}$.

Fitting the Stark spectra using derivatives of the observed absorption spectra was generally unsatisfactory, as only the compounds with the strongest donor groups yielded reasonable fits. Thus, we fit the IHCT transitions using two or three Gaussian peaks to fit the absorption spectra, and then used derivatives of each of the Gaussians to fit the Stark spectra. In some cases, large zeroth (and often first)-derivative components were observed to contribute to the Stark spectrum. In these cases, the fits with the zeroth-derivative component set to zero were performed. The results are discussed below (see Table 5).

First, the five HRS inactive imido-POMs (1-3, 6, and 7) all show minimal ( 0 to $9 \mathrm{~nm}$ ) red-shifts in $\lambda_{\max }$ in $\operatorname{PrCN}$ glasses versus room-temperature electronic spectra in $\mathrm{MeCN}$ or $\operatorname{PrCN}$. Visual inspection of the fits (Figure S11 in the SI) shows that most are dominated by first-derivative contributions relating to polarizability. The phenyliodo and phenylethynyl derivatives 1 and 2 consequently have zero values of $\Delta \mu_{12}, \beta_{0}$, etc., consistent with their lack of measurable HRS signal, and the qualitative conclusion that their transitions are highly delocalized and, at most, weakly dipolar in nature. This suggests that, in the absence of resonance donors/acceptors or extended conjugation, the lower-energy electronic transitions of arylimidoLindqvist anions are best seen as $\pi-\pi^{*}$ transitions perturbed and lowered in energy by participation from POM-oxo donor, and Mo d-orbital acceptor levels. This is broadly consistent with TD-DFT calculations (vide infra). Significant second derivative (CT) components emerge with extension of conjugation (6) and/or introduction of the $-\mathrm{NO}_{2}$ resonance acceptor group $(3,7)$, leading to small but appreciable values of
$\Delta \mu_{12} / \Delta \mu_{\mathrm{ab}}$ and more significant Stark-derived $\beta_{0}$. These are consistent with the larger $\pi$-systems and a CT component away from the POM and toward $-\mathrm{NO}_{2}$. Nonzero Stark $\beta_{0}$ values for HRS inactive POMs may arise because Stark spectroscopy does not take directional opposition between CT processes (e.g., aryl $\rightarrow$ POM, aryl $\rightarrow \mathrm{NO}_{2}$ ) into account, and because the dipolar character responsible for NLO activity is dampened by the highly delocalized nature of both aryl and POM moieties. Comparing 7 with the organic $-\mathrm{NO}_{2}$ analogue 13 , the much lower $\Delta \mu_{12}$ (and $\beta_{0}$ ) is consistent with the HRS inactivity of 7 , and Resonance Raman measurements that suggest weakened $\mathrm{CT}$ to $-\mathrm{NO}_{2}$ with a connected POM.

Compared to the inactive systems, the five HRS-active POMs $(4,5,8-10)$, and the organic chromophores $(12,13)$, all show more significant red-shifts of $10-35 \mathrm{~nm}$ in the PrCN glasses, with the trend in magnitude of red-shift matching the trend in $\beta_{0}$. This resembles the behavior of some organic charge transfer dyes, which have large thermochromic shifts associated with large excited-state dipole moments, and much smaller thermochromic shifts for less-polar systems. ${ }^{32}$ The fits (Figure S12 in the SI) also show more dipolar character for the active compounds, as second derivative contributions dominate at least one (in most cases, all) of the three Gaussians associated with the IHCT peak. This is reflected in $\Delta \mu_{12} / \Delta \mu_{\mathrm{ab}}$ values that are generally higher than in HRS inactive systems. Stark derived $\sum \beta_{0}$ (sum of all contributing Gaussians) values follow a very similar trend in magnitude to those from $1064 \mathrm{~nm}$ HRS, with extended $-\mathrm{NMe}_{2}$ derivative $\mathbf{1 0}$ giving the highest value of 280 $\times 10^{-30}$ esu and short pyrrole 4 showing the lowest value, at 47 $\times 10^{-30}$ esu. The similarity of the trends between the two techniques and the fact that the extended systems, which show more (albeit still weak) absorption at the $532 \mathrm{~nm}$ HRS SH wavelength and are hence more vulnerable to resonance effects, perform more strongly by Stark, implies that the HRSdetermined $\beta_{0}$ values are not enhanced by resonance. Trends within the HRS-active species follow expectations for the structure of the organic component: as donor strength and conjugation length increase, $\Delta \mu_{12} / \Delta \mu_{\mathrm{ab}}$ (averaged) increase, $H_{\mathrm{ab}}$ (D/A electronic coupling) decreases and $c_{\mathrm{b}}{ }^{2}$ moves further from the 0.5 associated with complete delocalization. Although the differences between individual compounds are often within Stark experimental errors, these findings are consistent with our other experimental observations (vide supra).

Stark data also help explain the high HRS $\beta_{0}$ of 4 and 5 versus organic analogue 12, and more similar behavior of 9 and 10 to that of 13. For extended system 10, Stark and HRS $\beta_{0}$ values are effectively within experimental error of those of nitro-analogue 13. Moreover, values of $\Delta \mu_{12}$ and $\Delta \mu_{\mathrm{ab}}$ differ by $10 \%$ or less, showing that, in $10, \mathrm{CT}$ distances are not extended by the POM. This fits with time-dependent density functional theory (TD-DFT) calculated acceptor orbitals for $\mathbf{1 0}$ that are distributed over the phenylimido ring as well as the POM (vide infra), and the simple consideration that, proportionally, the POM will have a smaller effect on CT distances in larger $\pi$ systems. In the short POM chromophore 5, however, $\sum \beta_{0}$ is dominated by the contribution of the middle Gaussian, which has $\Delta \mu_{12}=12.2 \mathrm{D}$, and a localized dipole moment change $\Delta \mu_{\mathrm{ab}}$ $=16.2 \mathrm{D}$ (CT distance $r_{\mathrm{ab}}=3.3 \AA$ ). These $\Delta \mu$ and $r$ values are ca. $40 \%-50 \%$ larger than for any of the Gaussians of the direct organic analogue 12, which is approximately twice the estimated experimental error. Combined with other experimental observations (for example, the pronounced red shift) and TD-DFT calculations, these increased $\Delta \mu$ and $r$ values 
imply that extension of charge transfer onto the POM increases charge separation in 4 and 5 vs $-\mathrm{NO}_{2}$ analogues. Thus, the unusually high intrinsic $\beta$ of $\mathbf{4}$ and $\mathbf{5}$ results from this increased charge separation, that occurs without the fall in electronic coupling associated with extended organic $\pi$-systems ( $H_{\mathrm{ab}}$ and $c_{\mathrm{b}}{ }^{2}$ for 5 and 12 are similar), or adding to the number of electrons in calculation of $\beta_{0} / N^{3 / 2}$.

DFT Calculations. TD-DFT calculations were performed using the SAOP XC potential and TZ2P basis set, through the Amsterdam Density Functional. ${ }^{33}$ These methods are a development of those previously published for organoimidoPOM NLO properties (LB94/TZP), ${ }^{10}$ and, in principle, an improvement due to the newer and more accurate $\mathrm{XC}$ potential $^{34}$ and larger basis set. Full details are given in the SI, including calculated electronic transitions and orbitals (Tables S4-S20, Figures S14-S27), and a comparison with prior calculations on the most similar compounds in the literature (see Chart S1 in the SI).

Our gas-phase calculations of $\beta_{0}$ yield results similar to those in the literature, ${ }^{10 \mathrm{c}-\mathrm{e}}$ and thus show trends at variance to those seen by experiment. The largest values are obtained for extended $-\mathrm{NO}_{2}$ derivative 7 (inactive by HRS) with the negative sign for $\beta_{z z z, 0}$ indicating that this arises from a net CT away from the POM, and toward the nitro group as described elsewhere. ${ }^{10 \mathrm{c}-\mathrm{e}}$ For other extended compounds, $\beta_{0}$ tends to decrease as donor strength increases-opposing the experimental trend. (See Table 6.) Calculated lowest transition

Table 6. DFT-Calculated Lowest-Energy Transitions and $\boldsymbol{\beta}_{0}$ Values for 1-10 in the Gas Phase

\begin{tabular}{ccccrr} 
& $\Delta E_{\mathrm{GE}}{ }^{a}$ & $f_{\mathrm{os}}$ & $S^{b}$ & \multicolumn{1}{c}{$\beta_{\mathrm{zzz}, 0}{ }^{c}$} & \multicolumn{1}{c}{$\beta_{\mathrm{vec}, 0}{ }^{d}$} \\
$\mathbf{1}$ & $3.12^{e}$ & $0.3125^{f}$ & $\mathrm{~A}$ & 19.3 & 10.1 \\
$\mathbf{2}$ & 3.04 & 0.3927 & $\mathrm{~A}$ & -7.8 & 7.1 \\
$\mathbf{3}$ & $2.75^{e}$ & $0.8070^{f}$ & $\mathrm{~A}$ & -52.7 & 32.4 \\
$\mathbf{4}$ & 3.10 & 0.3918 & $\mathrm{~A}$ & 10.9 & 5.0 \\
$\mathbf{5}$ & 2.92 & 0.1956 & $\mathrm{~A}$ & 37.1 & 19.8 \\
$\mathbf{6}$ & 2.46 & 1.5141 & $\mathrm{~A}$ & -355.7 & 215.7 \\
7 & $1.63^{e}$ & $0.9374^{f}$ & $\mathrm{~A}$ & -805.3 & 487.3 \\
$\mathbf{8}$ & 2.38 & 1.4441 & $\mathrm{~A}$ & -442.2 & 268 \\
$\mathbf{9}$ & 2.64 & 0.8468 & $\mathrm{~A}$ & -115.0 & 70.9 \\
$\mathbf{1 0}$ & $2.65^{e}$ & $1.8002^{f}$ & $\mathrm{~A}$ & -143.9 & 90.4
\end{tabular}

${ }^{a}$ Lowest energy transition. ${ }^{b}$ Symmetry. ${ }^{c}$ Dominant $\beta_{z z z}$ tensor component along the molecular axis. Negative values indicate that NLO effects originate from CT away from the POM. ${ }^{d}$ Orientationally averaged $\beta_{0}$ value. ${ }^{e}$ Weighted average of two or more closely spaced, similar transitions. ${ }^{f}$ Sum of two or more closely spaced, similar transitions.

energies $\Delta E_{\mathrm{GE}}$ also run counter to the experimental trend. For short compounds $\mathbf{1 - 5}$, calculated $\beta_{0}$ are a better match for experiment (plausible alternative Stark fits of 1 and $\mathbf{2}$ produce $\beta_{0}$ of ca. $10 \times 10^{-30} \mathrm{esu}$ ) but still the largest value is obtained for the $-\mathrm{NO}_{2}$ derivative 5. Analysis of TD-DFT orbital-toorbital transitions provides some points of qualitative agreement with values of $\Delta \mu$, etc., measured by Stark, while illustrating some of the disagreements with experiment. For example, the lowest energy transitions of $\mathbf{1}$ and $\mathbf{2}$ are essentially $\pi \rightarrow \pi^{*}$ transitions of the phenylimido group perturbed by the POM (Figures S14 and S15 in the Supporting Information), consistent with the minimal dipolar character observed through a low (or zero) Stark-determined $\Delta \mu_{12}$. In 5 (Figure S18) all transitions predominantly involve CT from a phenylimido- based HOMO to the POM, consistent with the much higher Stark $\Delta \mu_{12}$. However, for short $-\mathrm{NO}_{2}$ derivative 3 and all of the extended systems (see Tables S6 and S9-S13, and Figures S16 and S19-S23 in the SI), TD-DFT finds that the strongest lowenergy transition is from the phenylimido ring, toward the D/A ring, regardless of substituent. This agrees with previous calculations, ${ }^{10}$ but contradicts experiment. However, higherenergy CT processes, both toward and away from the POM, are also present, whose contribution varies with functionalization of the organic group.

To test whether these discrepancies originate from comparing gas-phase calculations with solution/glass-based measurements, we also calculated $\beta_{0}$ in an acetonitrile solvent force field. To our knowledge, such calculations have not been performed on organoimido-POMs before. They are unoptimized, but reproduce the experimental trend in $\beta$ for the HRS active compounds (Table S14 in the SI) while eliminating negative $\beta_{z z z}$ values for all but the $-\mathrm{NO}_{2}$ derivatives (which no longer have the largest magnitude). Moreover, calculated orbital-to-orbital transitions obtained on a subset (1, 3, 5, 10; see Tables S16-S19, and Figures S24 to S27 in the SI) show that CT to the POM becomes stronger and lower energy upon solvation, producing a picture that is, in most cases, qualitatively consistent with experiment. The effect is shown for $\mathbf{1 0}$ in Figure 6, and can be visualized in a simple way for all

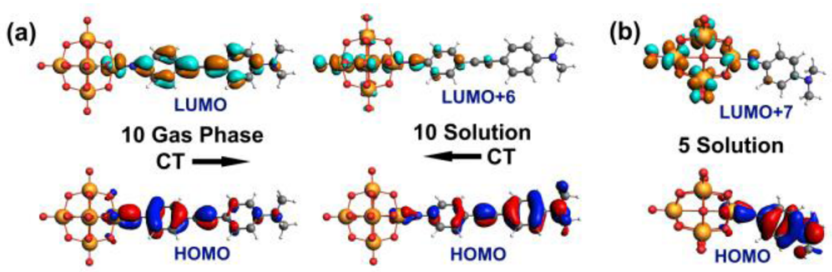

Figure 6. Strongest low energy orbital-to-orbital transitions in (a) compound $\mathbf{1 0}$ in the gas phase and in solution and (b) compound 5 in solution.

compounds through the calculated ground state dipole moments (Table S20). Notably, the calculated lowest energy transitions of $\mathbf{5}$ and $\mathbf{1 0}$ also reveal that the acceptor orbital spreads over the phenylimido ring of $\mathbf{1 0}$, but concentrates more on the POM in 5 , consistent with the increased $\Delta \mu_{12}$ vs nitro analogues observed for $\mathbf{5}$ but not $\mathbf{1 0}$ (Figure 6).

Even so, computed solution $\beta_{0}$ values for the active systems are approximately an order of magnitude larger than experiment, and significant values are found for inactive ones. It thus seems that in most cases CT to the POM is overestimated vs opposing CT processes. Calculated electronic spectra obtained for $1,3,5$, and 10 confirm this through a trend in $f_{\text {os }}$ with energy that is generally opposite to that measured by Stark, and also show an underestimate of transition energies. This will have a large effect, since in calculations $\beta_{0} \alpha 1 / \Delta E_{\mathrm{GE}}{ }^{310 \mathrm{~d}}$ Overall, experiment and computation reveal a complex mixture of CT and $\pi \rightarrow \pi^{*}$ processes whose strength, direction and energy varies with donor/acceptor, $\pi$-bridge, and solvation. Fully addressing this in silico will require the attention of theoreticians and computational specialists, as the large divergence from experiment makes the appropriateness of our methods an open question. However, prior work has shown reasonable agreement between similar methods to ours, several other DFT functionals, ${ }^{10 \mathrm{~d}}$ and Hartree-Fock calculations, ${ }^{10 \mathrm{e}}$ and we can identify two modifications that may improve results 
with our approach. One is to include $\mathrm{POM}-\mathrm{NBu}_{4}{ }^{+}$ion pairing in the solvation model, as this likely affects the interaction with acetonitrile. The other is to introduce conformational averaging of properties as the DFT optimized structures of 6-8 and 10 all show coplanar phenyl rings, but the energy barrier to rotation should be only ca. $1 \mathrm{kcal} \mathrm{mol}^{-1}$. $^{24}$ Indeed, a calculation on 10 in its crystallized geometry $\left(86^{\circ}\right.$ twist) lowers its solution $\beta_{0} 10$-fold. Future DFT computations on imido-POM $\beta$ may also be improved by larger basis sets with more diffuse functions.

\section{SUMMARY AND CONCLUSION}

Our results show that imido-Lindqvist clusters are an unusually efficient acceptor for use with short (phenyl) $\pi$-bridges in second-order NLO materials. With organic resonance electron donors, the resulting chromophores offer better transparency/ nonlinearity tradeoffs than similar purely organic systems and exceed empirical performance limits that apply to the vast majority of dipolar organic CT systems. However, extension of the chromophores by addition of a phenylacetylene spacer, while increasing absolute $\beta$-values, brings their performance back into line with comparable organic systems. Stark spectroscopy, supported by DFT calculations and Raman measurements, suggests that the unusually high intrinsic second order NLO activity of phenyl bridged systems arises because charge transfer extends onto the POM, giving unusually large dipole moment changes $(\Delta \mu)$ for the size of $\pi$-system. At the same time, donor/acceptor electronic coupling remains much higher than if $\Delta \mu$ were increased by extending the $\pi$-system. Thus, the POM acceptor can increase $\Delta \mu$, while sacrificing less transition strength than organic modifications used to achieve the same goal. In longer chromophores, the POM produces no gains over a nitro acceptor. This is most likely because acceptor orbitals spread onto the phenylimido ring, and proportionally the POM acceptor must have less effect on CT distances when the $\pi$-system is larger.

Compounds with no resonance donor, or with a resonance acceptor, show no NLO activity, despite similar electronic transition energies and extinction coefficients to active compounds. With no resonance donor or acceptor, both TDDFT results and the small to zero $\Delta \mu$ measured by Stark suggest that the electronic transitions are best described as $\pi \rightarrow$ $\pi^{*}$ transitions perturbed by POM O $2 p$ donor, and POM Mo $4 d$ acceptor orbitals, and hence lack sufficient CT character to be effective in quadratic NLO. With the $-\mathrm{NO}_{2}$ resonance acceptor, CT character measured by Stark increases, but not enough to explain the large DFT-computed $\beta_{0}$ values. The root of this computational inaccuracy appears to be (i) poor estimation of transition energies, and (ii) inaccurate estimation of the relative importance of transitions with directionally opposed dipole moment changes. While (ii) is improved by solvent correction, producing a similar trend to experimental data, (i) worsens producing inflated $\beta$ values. In future, this may be addressed by larger basis sets with more diffuse functions, improved solvent corrections, and rotational averaging for phenylacetylene bridges.

Now that the fundamentals underpinning the performance of imido-POM chromophores have been understood, future efforts will be directed at optimizing performance by tailoring the organic donor systems, and developing bulk NLO materials suitable for application in devices.

\section{ASSOCIATED CONTENT}

\section{S Supporting Information}

The Supporting Information is available free of charge on the ACS Publications website at DOI: 10.1021/acs.inorgchem.7b00708.

Full synthetic details and characterization including crystallographic details and CIF files for 1, 2, 5, 6, 7, and 10; additional Raman spectra; example Stark spectra and fits; details of DFT calculations, including pictorial representations of frontier orbitals and frontier orbital energies (PDF)

\section{Accession Codes}

CCDC 1553805-1553810 contain the supplementary crystallographic data for this paper. These data can be obtained free of charge via www.ccdc.cam.ac.uk/data_request/cif, or by Emailing data_request@ccdc.cam.ac.uk, or by contacting The Cambridge $\bar{C}$ rystallographic Data Centre, 12 Union Road, Cambridge CB2 1EZ, U.K.; fax: +44 1223336033.

\section{AUTHOR INFORMATION}

\section{Corresponding Author}

*E-mail: John.Fielden@uea.ac.uk.

ORCID

Joseph A. Wright: 0000-0001-9603-1001

John Fielden: 0000-0001-5963-7792

\section{Present Address}

"University of Hail, Faculty of Science, Department of Chemistry, P.O. Box 2440, Hail, Saudi Arabia.

\section{Notes}

The authors declare no competing financial interest.

In addition to the Supporting Information and deposited CIF files, data can be accessed by contacting the corresponding author.

\section{ACKNOWLEDGMENTS}

We thank the UK EPSRC National Crystallography Service in Southampton for X-ray data for 5, 7, and 10, the UK EPSRC National Mass Spectrometry Facility (Swansea) for MS, and the UK National Chemical Computing Service for access to $\mathrm{ADF}$ on Slater. This work was supported by the Iraqi Government (HCED scholarship to A.A.Y.), Royal Society of Chemistry, EPSRC (EP/M00452X/1), EU FP7 (Marie Curie IOF POMHYDCAT Contract No. 254339 to J.F.) and Fonds voor Wetenschappelijk Onderzoek-Vlaanderen (FWO-V, Ph.D. fellowship for N.V.S.). K.F. and H.K. would like to thank the BBSRC (No. BB/M018652/1) for funding. B.S.B. acknowledges support from the Beckman Institute of the California Institute of Technology. Stark data were collected and analyzed at the Molecular Materials Resource Center of the Beckman Institute of the California Institute of Technology.

\section{REFERENCES}

(1) (a) Polyoxometalates: From Platonic Solids to Anti-Retroviral Activity; Pope, M. T., Müller, A., Eds.; Kluwer Academic Publishers: Dordrecht, The Netherlands, 1994. (b) Long, D.-L.; Burkholder, E.; Cronin, L. Polyoxometalate clusters, nanostructures and materials: From self-assembly to designer materials and devices. Chem. Soc. Rev. 2007, 36, 105. (c) Fielden, J.; Cronin, L. Coordination Clusters. In Encyclopedia of Supramolecular Chemistry; Atwood, J. L., Steed, J. W., Eds.; Taylor \& Francis: London, 2007. (d) Hill, C. L. Polyoxometalates-Multicomponent Molecular Vehicles To Probe Fundamental Issues and Practical Problems. Chem. Rev. 1998, 98, 1. 
(e) Long, D.-L.; Cronin, L. Pushing the frontiers in polyoxometalate and metal oxide cluster science. Dalton. Trans. 2012, 41, 9815.

(2) (a) Dolbecq, A.; Dumas, E.; Mayer, C. R.; Mialane, P. Hybrid Organic-Inorganic Polyoxometalate Compounds: From Structural Diversity to Applications. Chem. Rev. 2010, 110, 6009. (b) Proust, A.; Matt, B.; Villanneau, R.; Guillemot, G.; Gouzerh, P.; Izzet, G. Functionalization and post-functionalization: a step towards polyoxometalate-based materials. Chem. Soc. Rev. 2012, 41, 7605. (c) Zhang, J.; Xiao, F.; Hao, J.; Wei, Y. The chemistry of organoimido derivatives of polyoxometalates. Dalton Trans. 2012, 41, 3599. (d) Proust, A.; Thouvenot, R.; Gouzerh, P. Functionalization of polyoxometalates: Towards advanced applications in catalysis and materials science. Chem. Commun. 2008, 1837.

(3) (a) Judeinstein, P. Synthesis and properties of polyoxometalates based inorganic-organic polymers. Chem. Mater. 1992, 4, 4. (b) Xu, B.; Lu, M.; Kang, J.; Wang, D.; Brown, J.; Peng, Z. Synthesis and Optical Properties of Conjugated Polymers Containing Polyoxometalate Clusters as Side-Chain Pendants. Chem. Mater. 2005, 17, 2841. (c) Lu, M.; Xie, B.; Kang, J.; Chen, F.-C.; Yang, Y.; Peng, Z. Synthesis of Main-Chain Polyoxometalate-Containing Hybrid Polymers and Their Applications in Photovoltaic Cells. Chem. Mater. 2005, 17, 402. (d) Chakraborty, S.; Keightley, A.; Dusevich, V.; Wang, Y.; Peng, Z. Synthesis and Optical Properties of a Rod-Coil Diblock Copolymer with Polyoxometalate Clusters Covalently Attached to the Coil Block. Chem. Mater. 2010, 22, 3995.

(4) (a) Bar-Nahum, I.; Cohen, H.; Neumann, R. OrganometallicPolyoxometalate Hybrid Compounds: Metallosalen Compounds Modified by Keggin Type Polyoxometalates. Inorg. Chem. 2003, 42, 3677. (b) Araghi, M.; Mirkhani, V.; Moghadam, M.; Tangestaninejad, S.; Mohammdpoor-Baltork, I. Synthesis and characterization of a new porphyrin-polyoxometalate hybrid material and investigation of its catalytic activity. Dalton Trans. 2012, 41, 3087.

(5) (a) Bonchio, M.; Carraro, M.; Scorrano, G.; Bagno, A. Photooxidation in Water by New Hybrid Molecular Photocatalysts Integrating an Organic Sensitizer with a Polyoxometalate Core. Adv. Synth. Catal. 2004, 346, 648. (b) Allain, C.; Favette, S.; Chamoreau, L.M.; Vaissermann, J.; Ruhlmann, L.; Hasenknopf, B. Hybrid OrganicInorganic Porphyrin-Polyoxometalate Complexes. Eur. J. Inorg. Chem. 2008, 2008, 3433.

(6) (a) Odobel, F.; Séverac, M.; Pellegrin, Y.; Blart, E.; Fosse, C.; Cannizzo, C.; Mayer, C. R.; Elliott, K. J.; Harriman, A. Coupled Sensitizer-Catalyst Dyads: Electron-Transfer Reactions in a Perylene-Polyoxometalate Conjugate. Chem.-Eur. J. 2009, 15, 3130. (b) Harriman, A.; Elliott, K. J.; Alamiry, M. A. H.; Le Pleux, L.; Séverac, M.; Pellegrin, Y.; Blart, E.; Fosse, C.; Cannizzo, C.; Meyer, C. R.; Odobel, F. Intramolecular Electron Transfer Reactions Observed for Dawson-Type Polyoxometalates Covalently Linked to Porphyrin Residues. J. Phys. Chem. C 2009, 113, 5834. (c) Elliott, K. J.; Harriman, A.; Le Pleux, L.; Pellegrin, Y.; Blart, E.; Mayer, C. R.; Odobel, F. A porphyrin-polyoxometallate bio-inspired mimic for artificial photosynthesis. Phys. Chem. Chem. Phys. 2009, 11, 8767. (d) Matt, B.; Coudret, C.; Viala, C.; Jouvenot, D.; Loiseau, F.; Izzet, G.; Proust, A. Elaboration of Covalently Linked Polyoxometalates with Ruthenium and Pyrene Chromophores and Characteriation of Their Photophysical Properties. Inorg. Chem. 2011, 50, 7761. (e) Matt, B.; Xiang, X.; Kaledin, A. L.; Han, N.; Moussa, J.; Amouri, H.; Alves, S.; Hill, C. L.; Lian, T.; Musaev, D. G.; Izzet, G.; Proust, A. Long lived charge separation in iridium(III)-photosensitized polyoxometalates: Synthesis, photophysical and computational studies of organometallicredox tunable oxide assemblies. Chem. Sci. 2013, 4, 1737.

(7) Matt, B.; Fize, J.; Moussa, J.; Amouri, H.; Pereira, A.; Artero, V.; Izzet, G.; Proust, A. Charge photo-accumulation and photocatalytic hydrogen evolution under visible light at an iridium(III)-photosensitized polyoxotungstate. Energy Environ. Sci. 2013, 6, 1504.

(8) (a) Strong, J. B.; Yap, G. P. A.; Ostrander, R.; Liable-Sands, L. M.; Rheingold, A. L.; Thouvenot, R.; Gouzerh, P.; Maatta, E. A. A New Class of Functionalized Polyoxometalates: Synthetic, Structural, Spectroscopic, and Electrochemical Studies of Organoimido Derivatives of $\left[\mathrm{Mo}_{6} \mathrm{O}_{19}\right]^{2-}$. J. Am. Chem. Soc. 2000, 122, 639. (b) Xu, B.; Wei,
Y.; Barnes, C. L.; Peng, Z. Hybrid Molecular Materials Based on Covalently Linked Inorganic Polyoxometalates and Organic Conjugated Systems. Angew. Chem., Int. Ed. 2001, 40, 2290.

(9) (a) Wei, Y.; Xu, B.; Barnes, C. L.; Peng, Z. An Efficient and Convenient Reaction Protocol to Organoimido Derivatives of Polyoxometalates. J. Am. Chem. Soc. 2001, 123, 4083. (b) Xu, L.; Lu, M.; Xu, B.; Wei, Y.; Peng, Z.; Powell, D. R. Towards Main-ChainPolyoxometalate-Containing Hybrid Polymers: A Highly Efficient Approach to Bifunctionalized Organoimido Derivatives of Hexamolybdates. Angew. Chem., Int. Ed. 2002, 41, 4129. (c) Lv, C.; Khan, R. N. N.; Zhang, J.; Hu, J.; Hao, J.; Wei, Y. Bifunctionalization of Polyoxometalates with Two Different Organoimido Ligands. Chem.-Eur. J. 2013, 19, 1174.

(10) (a) Yan, L.; Yang, G.; Guan, W.; Su, Z.; Wang, R. Density Functional Theory Study on the First Hyperpolarizabilities of Organoimido Derivatives of Hexamolybdates. J. Phys. Chem. B 2005, 109, 22332. (b) Yang, G.; Guan, W.; Yan, L.; Su, Z.; Xu, L.; Wang, E. B. Theoretical Study on the Electronic Spectrum and the Origin of Remarkably Large Third-Order Nonlinear Optical Properties of Organoimide Derivatives of Hexamolybdates. J. Phys. Chem. B 2006, 110, 23092. (c) Janjua, M. R. S. A.; Amin, M.; Ali, M.; Bashir, B.; Khan, M. U.; Iqbal, M. A.; Guan, W.; Yan, L.; Su, Z.-M. A DFT Study on The Two-Dimensional Second-Order Nonlinear Optical (NLO) Response of Terpyridine-Substituted Hexamolybdates: Physical Insight on 2D Inorganic-Organic Hybrid Functional Materials. Eur. J. Inorg. Chem. 2012, 2012, 705. (d) Janjua, M. R. S. A. Quantum Mechanical Design of Efficient Second-Order Nonlinear Optical Materials Based on Heteroaromatic Imido-Substituted Hexamolybdates: First Theoretical Framework of POM-Based Heterocyclic Aromatic Rings. Inorg. Chem. 2012, 51, 11306. (e) Janjua, M. R. S. A.; Khan, M. U.; Bashir, B.; Iqbal, M. A.; Song, Y.; Naqvi, S. A. R.; Khan, Z. A. Effect of $\pi$-conjugation spacer on the first hyperpolarizabilities of polymeric chain containing polyoxometalate cluster as a side-chain pendant: A DFT study. Comput. Theor. Chem. 2012, 994, 34.

(11) (a) Marder, S. R.; Perry, J. W.; Schaefer, W. P. Synthesis of Organic Salts with Large Second-Order Optical Nonlinearities. Science 1989, 245, 626. (b) Coe, B. J.; Harris, J. A.; Asselberghs, I.; Clays, K.; Olbrechts, G.; Persoons, A.; Hupp, J. T.; Johnson, R. C.; Coles, S. J.; Hursthouse, M. B.; Nakatani, K. Quadratic Nonlinear Optical Properties of N-Aryl Stilbazolium Dyes. Adv. Funct. Mater. 2002, 12, 110. (c) Coe, B. J.; Harris, J. A.; Asselberghs, I.; Wostyn, K.; Clays, K.; Persoons, A.; Brunschwig, B. S.; Coles, S. J.; Gelbrich, T.; Light, M. E.; Hursthouse, M. B.; Nakatani, K. Quadratic Optical Nonlinearities of N-Methyl and N-Aryl Pyridinium Salts. Adv. Funct. Mater. 2003, 13, 347. (d) Coe, B. J.; Fielden, J.; Foxon, S. P.; Helliwell, M.; Asselberghs, I.; Clays, K.; De Mey, K.; Brunschwig, B. S. Syntheses and Properties of Two-Dimensional, Dicationic Nonlinear Optical Chromophores Based on Pyrazinyl Cores. J. Org. Chem. 2010, 75, 8550. (e) Jang, S.H.; Luo, J.; Tucker, N. M.; Leclercq, A.; Zojer, E.; Haller, M. A.; Kim, T.-D.; Kang, J.-W.; Firestone, K.; Bale, D.; Lao, D.; Benedict, J. B.; Cohen, D.; Kaminsky, W.; Kahr, B.; Brédas, J.-L.; Reid, P.; Dalton, L. R.; Jen, A. K.-Y. Pyrroline Chromophores for Electro-Optics. Chem. Mater. 2006, 18, 2982. (f) Coe, B. J.; Fielden, J.; Foxon, S. P.; Harris, J. A.; Helliwell, M.; Brunschwig, B. S.; Asselberghs, I.; Clays, K.; Garín, J.; Orduna, J. Diquat Derivatives: Highly Active, Two-Dimensional Nonlinear Optical Chromophores with Potential Redox Switchability. J. Am. Chem. Soc. 2010, 132, 10498. (g) Coe, B. J.; Fielden, J.; Foxon, S. P.; Helliwell, M.; Brunschwig, B. S.; Asselberghs, I.; Clays, K.; Olesiak, J.; Matczyszyn, K.; Samoc, M. Quadratic and Cubic Nonlinear Optical Properties of Salts of Diquat-Based Chromophores with Diphenylamino Substituents. J. Phys. Chem. A 2010, 114, 12028. (h) Cheng, L. T.; Tam, W.; Stevenson, S. H.; Meredith, G. R.; Rikken, G.; Marder, S. R. Experimental investigations of organic molecular nonlinear optical polarizabilities. 1. Methods and results on benzene and stilbene derivatives. J. Phys. Chem. 1991, 95, 10631. (i) Cheng, L. T.; Tam, W.; Marder, S. R.; Stiegman, A. E.; Rikken, G.; Spangler, C. W. Experimental investigations of organic molecular nonlinear optical 
polarizabilities. 2. A study of conjugation dependences. J. Phys. Chem. 1991, 95, 10643.

(12) (a) Nonlinear Optics of Organic Molecules and Polymers; Nalwa, H. S., Miyata, S., Eds.; CRC Press: Boca Raton, FL, 1997. (b) Marder, S. R. Organic nonlinear optical materials: Where we have been and where we are going. Chem. Commun. 2006, 131. (c) Kuzyk, M. G. Using fundamental principles to understand and optimize nonlinearoptical materials. J. Mater. Chem. 2009, 19, 7444.

(13) (a) Dhenaut, C.; Ledoux, I.; Samuel, I. D. W.; Zyss, J.; Bourgault, M.; Le Bozec, H. Chiral metal complexes with large octupolar optical nonlinearities. Nature 1995, 374, 339. (b) McDonagh, A. M.; Humphrey, M. G.; Samoc, M.; Luther-Davies, B.; Houbrechts, S.; Wada, T.; Sasabe, H.; Persoons, A. Organometallic Complexes for Nonlinear Optics. 16. ${ }^{1}$ Second and Third Order Optical Nonlinearities of Octopolar Alkynylruthenium Complexes. J. Am. Chem. Soc. 1999, 121, 1405. (c) Di Bella, S. Second-order nonlinear optical properties of transition metal complexes. Chem. Soc. Rev. 2001, 30, 355. (d) Coe, B. J.; Fielden, J.; Foxon, S. P.; Brunschwig, B. S.; Asselberghs, I.; Clays, K.; Samoc, A.; Samoc, M. Combining Very Large Quadratic and Cubic Nonlinear Optical Responses in Extended, Tris-Chelate Metallochromophores with Six $\pi$-Conjugated Pyridinium Substituents. J. Am. Chem. Soc. 2010, 132, 3496. (e) Maury, O.; Le Bozec, H. Molecular Engineering of Octupolar NLO Molecules and Materials Based on Bipyridyl Metal Complexes. Acc. Chem. Res. 2005, 38, 691. (f) Le Bozec, H.; Renouard, T. Dipolar and Non-Dipolar Pyridine and Bipyridine Metal Complexes for Nonlinear Optics. Eur. J. Inorg. Chem. 2000, 2000, 229. (g) Alcaraz, G.; Euzenat, L.; Mongin; Katan, C.; Ledoux, I.; Zyss, J.; Blanchard-Desce, M.; Vaultier, M. Improved transparency-nonlinearity trade-off with boroxine-based octupolar molecules. Chem. Commun. 2003, 2766. (h) Kang, H.; Zhu, P.; Yang, Y.; Facchetti, A.; Marks, T. J. Self-Assembled Electrooptic Thin Films with Remarkably Blue-Shifted Optical Absorption Based on an XShaped Chromophore. J. Am. Chem. Soc. 2004, 126, 15974.

(14) Al-Yasari, A.; Van Steerteghem, N.; El Moll, H.; Clays, K.; Fielden, J. Donor-acceptor organo-imido polyoxometalates: high transparency, high activity redox-active NLO chromophores. Dalton Trans. 2016, 45, 2818.

(15) Tripathy, K.; Pérez Moreno, J.; Kuzyk, M. G.; Coe, B. J.; Clays, K.; Kelley, A. M. Why hyperpolarizabilities fall short of the fundamental quantum limits. J. Chem. Phys. 2004, 121, 7932.

(16) (a) Kang, H.; Facchetti, A.; Jiang, H.; Cariati, E.; Righetto, S.; Ugo, R.; Zuccaccia, C.; Macchioni, A.; Stern, C. L.; Liu, Z.; Ho, S. T.; Brown, E. C.; Ratner, M. A.; Marks, T. J. Ultralarge Hyperpolarizability Twisted $\pi$-Electron System Electro-Optic Chromophores: Synthesis, Solid-State and Solution-Phase Structural Characteristics, Electronic Structures, Linear and Nonlinear Optical Properties, and Computational Studies. J. Am. Chem. Soc. 2007, 129, 3267. (b) Shi, Y.; Frattarelli, D.; Watanabe, N.; Facchetti, A.; Cariati, E.; Righetto, S.; Tordin, E.; Zuccaccia, C.; Macchioni, A.; Wegener, S. L.; Stern, C. L.; Ratner, M. A.; Marks, T. J. Ultra-High-Response, Multiply Twisted Electro-optic Chromophores: Influence of $\pi$-System Elongation and Interplanar Torsion on Hyperpolarizability. J. Am. Chem. Soc. 2015, $137,12521$.

(17) Beverina, L.; Sanguineti, A.; Battagliarin, G.; Ruffo, R.; Roberto, D.; Righetto, S.; Soave, R.; Lo Presti, L.; Ugo, R.; Pagani, G. A. UV absorbing zwitterionic pyridinium-tetrazolate: exceptional transparency/optical nonlinearity trade-off. Chem. Commun. 2011, 47, 292.

(18) (a) Clays, K.; Persoons, A. Hyper-Rayleigh scattering in solution. Phys. Rev. Lett. 1991, 66, 2980. (b) Clays, K.; Persoons, A. Hyper-Rayleigh scattering in solution. Rev. Sci. Instrum. 1992, 63, 3285. (c) Hendrickx, E.; Clays, K.; Persoons, A. Hyper-Rayleigh Scattering in Isotropic Solution. Acc. Chem. Res. 1998, 31, 675.

(19) (a) Olbrechts, G.; Strobbe, R.; Clays, K.; Persoons, A. Highfrequency demodulation of multi-photon fluorescence in hyperRayleigh scattering. Rev. Sci. Instrum. 1998, 69, 2233. (b) Olbrechts, G.; Wostyn, K.; Clays, K.; Persoons, A. High-frequency demodulation of multiphoton fluorescence in long-wavelength hyper-Rayleigh scattering. Opt. Lett. 1999, 24, 403. (c) Clays, K.; Wostyn, K.; Olbrechts, G.; Persoons, A.; Watanabe, A.; Nogi, K.; Duan, X.-M.;
Okada, S.; Oikawa, H.; Nakanishi, H.; Vogel, H.; Beljonne, D.; Brédas, J.-L. Fourier analysis of the femtosecond hyper-Rayleigh scattering signal from ionic fluorescent hemicyanine dyes. J. Opt. Soc. Am. B 2000, 17, 256. (d) Franz, E.; Harper, E. C.; Coe, B. J.; Zahradnik, P.; Clays, K.; Asselberghs, I. Benzathiazoliums and pyridiniums for second-order nonlinear optics. Proc. SPIE 2008, 6999, 699923-1699923-11.

(20) Campo, J.; Desmet, F.; Wenseleers, W.; Goovaerts, E. Highly sensitive setup for tunable wavelength hyper-Rayleigh scattering with parallel detection and calibration data for various solvents. Opt. Express 2009, 17, 4587.

(21) (a) Shin, Y. K.; Brunschwig, B. S.; Creutz, C.; Sutin, N. Electroabsorption Spectroscopy of Charge-Transfer States of Transition-Metal Complexes. 2. Metal-to-Ligand and Ligand-to-Metal Charge-Transfer Excited States of Pentaammineruthenium Complexes. J. Phys. Chem. 1996, 100, 8157. (b) Coe, B. J.; Harris, J. A.; Brunschwig, B. S. Electroabsorption Spectroscopic Studies of Dipolar Ruthenium(II) Complexes Possessing Large Quadratic Nonlinear Optical Responses. J. Phys. Chem. A 2002, 106, 897.

(22) (a) Liptay, W. In Excited States, Vol. 1; Lim, E. C., Ed.; Academic Press: New York, 1974; pp 129-229. (b) Bublitz, G. U.; Boxer, S. G. Stark Spectroscopy: Applications in Chemistry, Biology, and Materials Science. Annu. Rev. Phys. Chem. 1997, 48, 213. (c) Vance, F. W.; Williams, R. D.; Hupp, J. T. Electroabsorption spectroscopy of molecular inorganic compounds. Int. Rev. Phys. Chem. 1998, 17, 307. (d) Brunschwig, B. S.; Creutz, C.; Sutin, N. Electroabsorption spectroscopy of charge transfer states of transition metal complexes. Coord. Chem. Rev. 1998, 177, 61.

(23) Xiao, Z.; Zhu, Y.; Wei, Y.; Wang, Y. Synthesis and characteristic of a new arylimido derivative of hexamolybdate with remote strong electro-donating group $\left(\mathrm{Bu}_{4} \mathrm{~N}\right)_{2}\left[\mathrm{Mo}_{6} \mathrm{O}_{18} \mathrm{NC}_{6} \mathrm{H}_{4} \mathrm{~N}\left(\mathrm{CH}_{3}\right)_{2-\mathrm{p}}\right]$. Inorg. Chem. Commun. 2006, 9, 400.

(24) (a) Lin, V. S.; Therien, M. J. The Role of Porphyrin-toPorphyrin Linkage Topology in the Extensive Modulation of the Absorptive and Emissive Properties of a Series of Ethynyl- and Butadiynyl-Bridged Bis- and Tris(porphinato)zinc Chromophores. Chem.-Eur. J. 1995, 1, 645. (b) LeCours, S. M.; DiMagno, S. G.; Therien, M. J. Exceptional Electronic Modulation of Porphyrins through meso-Arylethynyl Groups. Electronic Spectroscopy, Electronic Structure, and Electrochemistry of [5,15-Bis[(aryl)ethynyl]10,20-diphenylporphinato]zinc(II) Complexes. X-ray Crystal Structures of $\left[5,15-B i s\left[\left(4^{\prime}\right.\right.\right.$-fluorophenyl)ethynyl]-10,20diphenylporphinato $]$ zinc(II) and 5,15-Bis[(4'-methoxyphenyl)ethynyl]-10,20-diphenylporphyrin. J. Am. Chem. Soc. 1996, 118, 11854. (c) Kamat, N. P.; Liao, Z.; Moses, L. E.; Rawson, J.; Therien, M. J.; Dmochowski, I. J.; Hammer, D. A. Sensing membrane stress with near IR-emissive porphyrins. Proc. Natl. Acad. Sci. U. S. A. 2011, 108, 13984.

(25) (a) Barlow, S.; Marder, S. R. Electronic and optical properties of conjugated group 8 metallocene derivatives. Chem. Commun. 2000, 1555. (b) Kim, H. M.; Cho, B. R. Second-order nonlinear optical properties of octupolar molecules structure-property relationship. J. Mater. Chem. 2009, 19, 7402. (c) Hennrich, G.; Asselberghs, I.; Clays, K.; Persoons, A. Tuning Octopolar NLO Chromophores: Synthesis and Spectroscopic Characterization of Persubstituted 1,3,5-Tris(ethynylphenyl)benzenes. J. Org. Chem. 2004, 69, 5077. (d) Cheng, L. T.; Tam, W.; Marder, S. R.; Stiegman, A. E.; Rikken, G.; Spangler, C. W. Experimental investigations of organic molecular nonlinear optical polarizabilities. 2. A study of conjugation dependences. J. Phys. Chem. 1991, 95, 10643. (e) Lee, J. Y.; Suh, S. B.; Kim, K. S. Polyenes vs polyynes: Efficient $\pi$-frame for nonlinear optical pathways. J. Chem. Phys. 2000, 112, 344. (f) Champagne, B.; Kirtman, B. Vibrational versus electronic first hyperpolarizabilities of $\pi$-conjugated organic molecules: an ab initio Hartree-Fock investigation upon the effects of the nature of the linker. Chem. Phys. 1999, 245, 213.

(26) Flipse, M. C.; De Jonge, R.; Woudenberg, R. H.; Marsman, A. W.; Van Walree, C. A.; Jenneskens, L. W. The determination of first hyperpolarizabilities $\beta$ using hyper-Rayleigh scattering: A caveat. Chem. Phys. Lett. 1995, 245, 297. 
(27) (a) Walsh, J. T.; Mallon, C. T.; Bond, A. M.; Keyes, T. E.; Forster, R. J. Enhanced photocurrent production from thin films of $\mathrm{Ru}(\mathrm{II})$ metallopolymer/Dawson polyoxotungstate adducts under visible irradiation. Chem. Commun. 2012, 48, 3593. (b) Walsh, J. J.; Long, D.-L.; Cronin, L.; Bond, A. M.; Forster, R. J.; Keyes, T. E. Electronic and photophysical properties of adducts of $\left[\mathrm{Ru}(\mathrm{bpy})_{3}\right]^{2+}$ and Dawson-type sulfite polyoxomolybdates $\alpha / \beta-\left[\mathrm{Mo}_{18} \mathrm{O}_{54}\left(\mathrm{SO}_{3}\right)_{2}\right]^{4-}$. Dalton Trans. 2011, 40, 2038. (c) Keyes, T. E.; Gicquel, E.; Guerin, L.; Forster, R. J.; Hultgren, V. M.; Bond, A. M.; Wedd, A. G. Photophysical and Novel Charge-Transfer Properties of Adducts between $\left[\mathrm{Ru}^{\mathrm{II}}(\mathrm{bpy})^{3}\right]^{2+}$ and $\left[\mathrm{S}_{2} \mathrm{Mo}_{18} \mathrm{O}_{62}\right]^{4-}$. Inorg. Chem. 2003, 42, 7897. (d) Walsh, J. J.; Long, D.-L.; Cronin, L.; Bond, A. M.; Forster, R. J.; Keyes, T. E. Electronic and photophysical properties of adducts of $\left[\mathrm{Ru}(\mathrm{bpy})_{3}\right]^{2+}$ and Dawson-type sulfite polyoxomolybdates $\alpha / \beta$ $\left[\mathrm{Mo}_{18} \mathrm{O}_{54}\left(\mathrm{SO}_{3}\right)_{2}\right]^{4-}$. Dalton Trans. 2011, 40, 2038. (e) Zhu, J.; Zeng, Q.; O'Carroll, S.; Bond, A. M.; Keyes, T. E.; Forster, R. J. Photocurrent generation from thin films of ruthenium metallopolymer:polyoxometalate adducts using visible excitation. Electrochem. Commun. 2011, 13, 899.

(28) (a) Bridgeman, A. J.; Cavigliasso, G. Density functional study of the vibrational frequencies of Lindqvist polyanions. Chem. Phys. 2002, 279, 143. (b) Buckley, R. I.; Clark, R. J. H. Structural and electronic properties of some polymolybdates reducible to molybdenum blues. Coord. Chem. Rev. 1985, 65, 167. (c) Mattes, R.; Bierbüsse, H.; Fuchs, J. Schwingungsspektren und Kraftkonstanten von Polyanionen mit $\mathrm{M}_{6} \mathrm{O}_{19}$-Gruppen. Z. Anorg. Allg. Chem. 1971, 385, 230. (d) Rocchiccioli-Deltcheff, C.; Thouvenot, R.; Fouassier, M. Vibrational investigations of polyoxometallates. 1 . Valence force field of $\mathrm{Mo}_{6} \mathrm{O}_{19}{ }^{2-}$ based on total isotopic substitution (oxygen-18, molybdenum-92, molybdenum-100). Inorg. Chem. 1982, 21, 30.

(29) She, S.; Bian, S.; Hao, J.; Zhang, J.; Zhang, J.; Wei, Y. Aliphatic Organoimido Derivatives of Polyoxometalates Containing a Bioactive Ligand. Chem.-Eur. J. 2014, 20, 16987.

(30) Osipov, V. G.; Shlyapochnikov, V. A.; Ponizovtsev, E. F. Vibrational spectra of aromatic nitro compounds. J. Appl. Spectrosc. 1968, 8, 598.

(31) Coe, B. J.; Harris, J. A.; Clays, K.; Persoons, A.; Wostyn, A.; Brunschwig, B. S. A comparison of the pentaammine(pyridyl)ruthenium(II) and 4-(dimethylamino)phenyl groups as electron donors for quadratic non-linear optics. Chem. Commun. 2001, 1548.

(32) Suppan, P.; Tsiamis, C. J. Temperature effects in solvatochromic shifts. J. Chem. Soc., Faraday Trans. 2 1981, 77, 1553.

(33) (a) te Velde, G.; Bickelhaupt, F. M.; Baerends, E. J.; Fonseca Guerra, C.; van Gisbergen, S. J. A.; Snijders, J. G.; Ziegler, T. Chemistry with ADF. J. Comput. Chem. 2001, 22, 931. (b) Fonseca Guerra, C.; Snijders, J. G.; Te Velde, G.; Baerrends, E. Towards an order-N DFT method. J. Theor. Chem. Acc. 1998, 99, 391. (c) ADF2014.10, SCM, Theoretical Chemistry, Vrije Universiteit, Amsterdam, The Netherlands, http://www.scm.com.

(34) (a) Gritsenko, O. V.; Schipper, P. R. T.; Baerends, E. J. Approximation of the exchange-correlation Kohn-Sham potential with a statistical average of different orbital model potentials. Chem. Phys. Lett. 1999, 302, 199. (b) Schipper, P. R. T.; Gritsenko, O. V.; van Gisbergen, S. J. A.; Baerends, E. J. Molecular calculations of excitation energies and (hyper)polarizabilities with a statistical average of orbital model exchange-correlation potentials. J. Chem. Phys. 2000, 112, 1344. 